\title{
Critical appraisal of eculizumab for atypical hemolytic uremic syndrome
}

This article was published in the following Dove Press journal:

Journal of Blood Medicine

12 April 2016

Number of times this article has been viewed

\author{
Lilian M Pereira Palma' \\ Craig B Langman ${ }^{2}$ \\ 'Pediatric Nephrology, State \\ University of Campinas (UNICAMP), \\ Campinas, São Paulo, Brazil; ${ }^{2}$ The \\ Feinberg School of Medicine, \\ Northwestern University, and the \\ Ann and Robert H. Lurie Children's \\ Hospital of Chicago, Chicago, IL, USA
}

\begin{abstract}
The biology of atypical hemolytic uremic syndrome has been shown to involve inability to limit activation of the alternative complement pathway, with subsequent damage to systemic endothelial beds and the vasculature, resulting in the prototypic findings of a thrombotic microangiopathy. Central to this process is the formation of the terminal membrane attack complex C5b-9. Recently, application of a monoclonal antibody that specifically binds to $\mathrm{C} 5$, eculizumab, became available to treat patients with atypical hemolytic uremic syndrome, replacing plasma exchange or infusion as primary therapy. This review focuses on the evidence, based on published clinical trials, case series, and case reports, on the efficacy and safety of this approach.
\end{abstract}

Keywords: acute kidney injury, ESRD, thrombotic microangiopathy, kidney, alternative complement pathway, complement blockade

\section{Introduction}

This article is designed to provide a critical appraisal of the efficacy and safety of eculizumab in atypical hemolytic uremic syndrome (aHUS) in children and adults. We analyze published work based on the level of evidence from controlled trials through anecdotal case series and individual case reports. A MEDLINE search was performed to identify all relevant articles using the terms "atypical hemolytic uremic syndrome or aHUS" and "eculizumab." We will review why it has become the treatment of choice for aHUS, and current limitations in the data.

Clinically, thrombotic microangiopathy (TMA) can occur in a number of diseases. However, the most commonly associated diseases are hemolytic uremic syndrome (HUS, either shiga-toxin-associated or aHUS), thrombotic thrombocytopenic purpura (TTP), and disseminated intravascular coagulation. HUS is characterized by the triad of microangiopathic hemolytic anemia (MAHA), thrombocytopenia, and moderate to severe acute kidney injury, while TTP is defined by the pentad of MAHA, severe thrombocytopenia, fever, and, commonly, neurological impairment and milder acute kidney injury than in HUS, although such features may occur in HUS as well. Disseminated intravascular coagulation is rather distinct clinically, with the presence of an abnormal coagulation profile predominating, and often associated with sepsis.

aHUS is a prototypic TMA, caused by an inability to stop alternative pathway (AP) complement activation of the terminal membrane attack complex (MAC, C5b-9), thereby leading to damage of endothelial cell beds through the body, as well as the inability to block platelet and white blood cell activation in the circulation, which adds 
further to the microangiopathic process. ${ }^{1}$ There is a clear genetic underpinning documented in nearly two-thirds of aHUS cases, relating to an inactivating mutation in proteins that downregulate AP activity (factor $\mathrm{H}$, factor I, membrane cofactor protein [MCP or CD-46], thrombomodulin), or with an activating mutation in $\mathrm{C} 3$ or factor $\mathrm{B}$ that renders them constitutively overactive and not subject to modulation of activity, or through the formation of anti-factor $\mathrm{H}$ immunoglobulin $\mathrm{G}$ (IgG) antibodies (which commonly are associated with gene rearrangements or deletions in complement factor $\mathrm{H}[\mathrm{CFH}]$-related protein-1 and -3), all of which lead to AP generation of the MAC.

Additional cases of aHUS may be seen in a variety of circumstances that lead to AP complement overactivity coupled with the absence of sufficient regulation, including systemic lupus erythematosus, scleroderma, malignant hypertension, drugs, ${ }^{2-4}$ and pregnancy, among other conditions. A recent study $^{5}$ of 193 patients that employed a high-throughput genetic screening process demonstrated the ability to find most mutations and raised the question of novel genetic variants in the pathogenesis of aHUS as well. The combination of a "predisposing factor" (genetic mutations/variants) with a "precipitating factor" (infection, drug, systemic disease, and others) may overcome the ability to control AP and, therefore, leads to the onset of aHUS. In a recent paper, Jodele et $\mathrm{al}^{6}$ evaluated candidates for bone marrow transplant regarding genetic susceptibility to TMA and found that gene variants in complement regulators were more common among patients with transplant-associated TMA.

Common to aHUS, regardless of the cause, is the activation of the MAC, which starts with hydrolysis of complement factor $\mathrm{C} 5$ into $\mathrm{C} 5 \mathrm{a}$ and $\mathrm{C} 5 \mathrm{~b}$. The humanized monoclonal antibody, eculizumab, binds to the complement protein C5 with high affinity and inhibits its cleavage to C5a and $\mathrm{C} 5 \mathrm{~b}$, thereby preventing the subsequent generation of the MAC. Eculizumab contains the murine complementaritydetermining regions of the m5G1.1 monoclonal antibody, which were grafted onto the human framework light- and heavy-chain variable regions. The use of the germ line framework acceptor sequences was employed to minimize the potential for immunogenicity. The heavy-chain constant region of the parent antibody was replaced by components of both human $\mathrm{IgG}_{2}$ and $\mathrm{IgG}_{4}$ and, therefore, lacks the ability to activate complement and to bind Fc receptors. Such modifications should minimize the potential of eculizumab to induce pro-inflammatory responses. ${ }^{7,8}$

Eculizumab was approved in 2011 in the United States ${ }^{9}$ and shortly thereafter in Europe. ${ }^{10}$ Currently, the drug has been used worldwide for the treatment of aHUS. A recent consensus document ${ }^{11}$ almost uniformly recommended that, once the diagnosis of aHUS is made, eculizumab should be started immediately thereafter.

Reliable tools to monitor the response to eculizumab, outside of reversal of the clinical features of aHUS, are yet to be defined. In patients with paroxysmal nocturnal hemoglobinuria (PNH), a complement-mediated disease for which eculizumab was first approved, there seems to be a correlation between activity of 50\% hemolytic complement (CH50) assay $<10 \%$ and free eculizumab levels $>50 \mu \mathrm{g} / \mathrm{mL}$ with efficacy of the drug in reducing hemolysis. ${ }^{12}$ Although the use of $\mathrm{CH} 50$ is feasible in daily practice, there is no prospective data in patients with aHUS to confirm its usefulness, and a standard value to correlate with complement blockade is missing. In the National Health Service (NHS) Commissioning Policy on aHUS in England report, ${ }^{13}$ monitoring was done by both $\mathrm{CH} 50$ and AP (AP50) hemolytic assay, where complete absence of hemolytic activity was used as criteria for adequate complement blockade. Based on these criteria, only two out of 43 patients treated needed increased dosing of eculizumab (one child and one adult post-transplant). Jodele et al ${ }^{14}$ reported on the use of eculizumab to treat six children with severe hematopoietic stem cell transplant-TMA and adjusted the dose for a therapeutic level $>99 \mu \mathrm{g} / \mathrm{mL}$ with resolution in four of six children. In this study, $\mathrm{CH} 50$ was used to monitor the level of complement blockade (CH50 level $\leq 4$ complement activity enzyme units used in this series), and the authors found that children needed higher doses or smaller intervals of eculizumab infusions compared with the US FDA-approved regimen for children with aHUS. Two patients died despite dose intensification, but were critically ill. ${ }^{14}$

To assess the response to eculizumab in a different manner, and using retrospective data, Noris et $\mathrm{al}^{15}$ documented a different biomarker of C5 blockade in patients with aHUS, using an ex vivo test that employed vascular endothelial cells that predicted clinical effectiveness of eculizumab in vivo and might guide drug dosing and/or timing. In this study, the authors demonstrated that aHUS patients with or without identified complement gene mutations or anti-CFH antibodies consistently and chronically activate complement on endothelium. Using an in vitro system with adenosine diphosphate-activated endothelial cell culture, blood samples from patients diagnosed clinically with aHUS, with or without overt TMA, induced more C3 and C5b-9 deposition than control sera, documenting the higher sensitivity (100\%) of this ex vivo assay vs elevated plasma soluble (s)C5b-9 levels in detecting complement dysregulation in aHUS. In contrast, 
this did not happen in patients with $\mathrm{C} 3$ glomerulopathy in which the AP is dysregulated in the fluid phase, reinforcing the concept of an endothelial-restricted complement deposition in aHUS. C5b-9 deposits were prevented by the anti-C5 antibody eculizumab. More work remains to understand what biomarker of disease activity and efficacy of eculizumab therapy might be appropriate. aHUS-associated mutant proteins may often effectively regulate complement in the fluid (blood) phase, which would explain the normal or near-normal circulating C3 levels in many mutation carriers. Gain-of-function mutations of $\mathrm{CFB}$ and $\mathrm{C} 3$ form a $\mathrm{C} 3$ convertase resistant to decay by endothelial cell/membrane-bound regulators. Such findings provide strong evidence that aHUS is a disease of unrestricted endothelial complement activation.

\section{Treatment of aHUS in the pre-eculizumab era}

Following the landmark paper published by Bell et al in $1991,{ }^{16}$ plasma exchange/plasma infusion (PE/PI) became the initial treatment for most patients with aHUS. Initial reports ${ }^{17-19}$ presented variable outcomes of patients with HUS in case series or reports in which laboratory assessments for differential diagnosis between shigatoxin HUS, aHUS, or TTP were not available. More recently, Noris et al, ${ }^{20}$ in an analysis of 273 patients with either sporadic $(n=191)$ or familial ( $n=82$ ) aHUS and treated with PE/PI, found that twothirds of adult patients had a bad outcome (dialysis or death) in a 3-year follow-up, which varied according to genotype. They reported a mortality rate of $8 \%$ and $11 \%$, after first manifestation and 3 years of follow-up, respectively. Despite case reports of "good" outcomes with plasma therapy (three and five patients, respectively), ${ }^{21,22}$ in a recent report from the French group ( $n=214$ patients), the mortality rate was higher in children than adults ( $8 \%$ vs $2 \%$ ) after 4 years of followup, with fatal outcomes, despite initial plasma therapy. ${ }^{23,24}$ Cataland et al, ${ }^{25}$ in a retrospective registry analysis of 19 patients diagnosed with aHUS, found that only six of the 16 patients treated with PE/PI had a complete hematologic and kidney recovery (and in contrast to seven of the nine patients treated with eculizumab). Although the genotypephenotype correlation data indicate that $M C P$ mutations are associated with a better prognosis than $\mathrm{CFH}$ mutations, this is not always straightforward, since there are patients who present severe and life-threatening manifestations with different degrees of response to plasma therapy independently of having an identifiable mutation or not. ${ }^{22,26,27}$

Among the potential risk factors for apheresis-related complications in low-weight patients, such as children and small adults, are those related to the relatively large extracorporeal volume and the difficulties related to ensuring adequate vascular access. There is an almost $50 \%$ incidence of any adverse event including hypotension, symptomatic hypocalcemia, allergic reactions, and catheter-related thrombosis, and $1 \%$ death rate, in patients undergoing plasmaexchange therapies. ${ }^{28}$

De et $\mathrm{al}^{29}$ published a review of 28 pediatric cases of aHUS with identified mutations who were treated with supportive measures, PE/PI, kidney transplant ( $\pm \mathrm{PE} / \mathrm{PI})$, or liver/ combined liver-kidney transplantation in the pre-eculizumab era. Overall, 13 of the 28 patients either died or had a relapse, and 15 recovered and were well until last follow-up (the latter included five patients with $M C P$ mutations). Among the 20 patients with $\mathrm{CFH}$ mutations (homozygous or compound heterozygotes), ten either died or relapsed and ten recovered. Three patients with anti-factor $\mathrm{H}$ antibodies had poor outcomes (one needed dialysis and two had multiple relapses). The authors concluded that, despite major progress in the understanding of the underlying pathogenetic mechanisms, aHUS remains a severe childhood disease with potential adverse outcomes, including the development of end-stage renal disease (ESRD), disease recurrence after transplantation, and death.

\section{Analysis of the published data for eculizumab in aHUS \\ Prospective controlled trials of eculizumab in patients with aHUS}

In 2013, Legendre et al published the results of the first prospective trials of eculizumab in aHUS conducted in Europe and North America with patients 12 years of age or older. ${ }^{30}$ These trials had followed upon dozens of anecdotal reports of the use of eculizumab for the treatment of aHUS, which we review later in this article.

Patients were enrolled in two prospective trials according to levels of kidney and hematologic abnormalities:

Trial 1 ("progressive TMA"): kidney impairment (creatinine $\geq$ upper limit of normal [ULN]) and persistent thrombocytopenia $\left(<150 \times 10^{9} / \mathrm{L}\right)$ with evidence of hemolysis (low haptoglobin, presence of schistocytes, or lactate dehydrogenase $[\mathrm{LDH}] \geq \mathrm{ULN}$ ) despite four or more sessions of plasma therapy (PE/PI).

Trial 2 ("longstanding TMA"): kidney impairment (creatinine $\geq U L N$ ) with evidence of hemolysis (low haptoglobin, presence of schistocytes, or LDH $\geq$ ULN) and no platelet count decrease $>25 \%$ during 8 consecutive weeks during plasma therapy. 
Among other inclusion criteria were a disintegrin and metalloproteinase with a thrombospondin type 1 motif, member 13 (ADAMTS13) activity $>5 \%$, and shigatoxin negative in stools during enrollment screening. Gene mutations or anti-factor $\mathrm{H}$ antibodies were not a prerequisite.

While end points were different for each trial (Table $1^{30,31}$ ), common safety issues were assessed. Both groups received eculizumab for 26 weeks according to a previously predetermined dosing schedule ${ }^{9}$ and were allowed to continue in an extension-phase study, with the 2-year follow-up results published recently by Licht et al. ${ }^{31}$

In the "progressive TMA trial," the primary end point was to hinder "complement-mediated TMA," defined by a composite measure (Table 1). At the beginning of the trial, 17 patients (one adolescent) were enrolled, and the median interval between diagnosis of aHUS and screening was 9.7 months. Time from onset of the then-prevalent manifestation of TMA to screening was 0.8 months. ${ }^{31}$ Except for one patient, all received plasma therapy during the week before eculizumab was started. All patients had an eGFR (estimated glomerular filtration rate) below $60 \mathrm{~mL} / \mathrm{min} / 1.73 \mathrm{~m}^{2}$ for 17 days (median duration), while eleven patients received dialysis either before or at first dose of eculizumab, with a median (interquartile range) duration of 22 (1-27) days. In this study, seven patients had prior kidney transplants. No mutations or factor-H antibodies were found in $24 \%$ of

Table I Criteria for response to eculizumab in prospective trials

\begin{tabular}{ll}
\hline Inhibition of "complement-mediated & TMA event-free status \\
TMA" (progressive TMA trial) & $\begin{array}{l}\text { (longstanding TMA } \\
\text { trial) }\end{array}$
\end{tabular}

Normal platelet count and normal LDH No decrease in platelet

level sustained for at least two consecutive count of $>25 \%$, no plasma measurements over a period of at least exchange or infusion use, 4 weeks

Secondary end points included measures of renal function, changes in health-related quality of life, pharmacokinetics and pharmacodynamics, and safety and tolerability patients. Patients received eculizumab ranging from 2 weeks to 90 weeks in duration (median 64 weeks on treatment), and 15/17 patients completed 26 weeks of treatment.

Complete TMA response (criteria described in Table 1) was reached by $65 \%$ and $76 \%$ of patients at week 26 and 2 years, respectively. Many additional analyses were performed based on the data in this trial. Half of the patients with thrombocytopenia at baseline had a normal platelet count after 1 week, which remained normal at week 26 in almost $90 \%$ of patients. Normalization of platelet count and LDH levels occurred in near $90 \%$ of patients, and the great majority of patients enrolled did not receive PE or PI for the entire duration of the study. After eculizumab treatment, kidney function improved progressively with an eGFR increase of $32 \mathrm{~mL} / \mathrm{min} / 1.73 \mathrm{~m}^{2}$ from baseline to week 26 . In $80 \%$ of patients, dialysis was discontinued, and they remained dialysis-free through the treatment period (26 weeks).

Among the 15 patients with aHUS who completed 26 weeks of eculizumab, 13 were enrolled in the extension phase. ${ }^{31}$ At the 2-year time point, eleven of 13 patients remained on eculizumab (two had withdrawn because of decrease in kidney function). Platelet count was normalized in nearly $90 \%$ at the 1-year and 2-year cutoffs (two patients were withdrawn from the study before 26 weeks of treatment because of lack of improvement). Improvements in eGFR were maintained after the first year of this trial. eGFR increased from $33 \mathrm{~mL} / \mathrm{min} / 1.73 \mathrm{~m}^{2}$ to $37 \mathrm{~mL} / \mathrm{min} / 1.73 \mathrm{~m}^{2}$ between week 26 and the 2 -year cutoff, with an absolute mean (SD) eGFR of $56(40) \mathrm{mL} / \mathrm{min} / 1.73 \mathrm{~m}^{2}$ at 26 weeks, and 56 (30) $\mathrm{mL} / \mathrm{min} / 1.73 \mathrm{~m}^{2}$ at the 2 -year data analysis. Four of the five patients $(80 \%)$ were able to stop dialysis (one before the first dose of eculizumab and three at a mean of 1 week after the starting on eculizumab). One patient needed to start dialysis during the 26-week study period (this patient discontinued the study and was not included in the 2-year analysis). Another patient started dialysis on study day 444 , and also discontinued. In summary, two patients were on dialysis at the 2-year cutoff. ${ }^{31}$ There was the same number of transplanted patients, and none lost their graft.

In the second controlled trial, comprising "patients with longstanding TMA," ${ }^{30}$ patients were eligible for study entry if they had kidney impairment, stabilization in platelet count for at least 8 weeks before the first dose of eculizumab, and received plasma therapy at least once every 2 weeks (but no more than three times per week). The primary end point (Table 1) for this trial was "TMA event-free status" for at least 12 weeks in duration. The interval between diagnosis and screening was longer (median, 48.3 months) than seen 
in the progressive TMA trial discussed.$^{30}$ In the longstanding TMA trial, $35 \%$ of the participants had no identified mutation in AP complement or the presence of anti-factor $\mathrm{H}$ antibodies. The majority of patients had chronic renal disease (eGFR below $60 \mathrm{~mL} / \mathrm{min} / 1.73 \mathrm{~m}^{2}$ for a median of 75 months before treatment with eculizumab; two patients on dialysis), and with the majority of patients being treated with plasma therapy for 10 months (median). Time from onset of the clinical manifestation of aHUS to screening was 8.6 months (median), and all patients received PE/PI before eculizumab. The median (range) duration of dialysis during the current manifestation was $1.7(0.32-3)$ years. Eight patients had a prior kidney transplant. ${ }^{31}$

In this "longstanding TMA" trial, complete TMA response (criteria detailed in Table 1) increased from $25 \%$ at 26 weeks, to $55 \%$ at the 2 -year cutoff. Treatment with eculizumab varied in length from 26 weeks to 74 weeks (median 62 weeks). By week 26, 80\% of the patients met the primary study end point noted above; four patients did not achieve the proposed end point because of variations in platelet count, although levels were within normal limits. All patients stopped plasma therapy, and none started new dialysis.

After starting eculizumab, eGFR increased from $6 \mathrm{~mL} /$ $\mathrm{min} / 1.73 \mathrm{~m}^{2}$ to $9 \mathrm{~mL} / \mathrm{min} / 1.73 \mathrm{~m}^{2}$ between baseline and week 60; the absolute mean (SD) eGFR also increased from 37 (21) $\mathrm{mL} / \mathrm{min} / 1.73 \mathrm{~m}^{2}$ to 40 (18) $\mathrm{mL} / \mathrm{min} / 1.73 \mathrm{~m}^{2}$ at the 2-year time point. Thereafter, initial eGFR improvements were maintained during the 2-year eculizumab treatment. Two patients required dialysis at baseline: one was on dialysis at the 2-year analysis, and the other received hemodialysis until renal transplantation (on day 217). During the 2 years of the study, one patient started dialysis (days 695-696) during admission for an intestinal hemorrhage and died of that complication. There were no new kidney transplants or graft losses.

Of the 20 patients (five adolescents) who completed the initial 26-week study, 19 entered the extension period, with eculizumab continued up to 78 weeks. Eighteen patients remained on treatment with eculizumab until the data analysis at 2 years. ${ }^{31}$ The median (range) duration of eculizumab exposure in this trial was $0.31(0.07-0.35)$ years.

Both in the "Progressing TMA trial" and in the "Longstanding TMA trial," earlier initiation of eculizumab (time between the current manifestation and enrollment) was associated with a greater improvement in the eGFR. Eculizumab responses in the primary end points were seen in patients regardless of identified genetic mutations or $\mathrm{CFH}$ autoantibodies, both in the initial and extension phases. ${ }^{30,31}$

In both trials, a significant improvement in health-related quality of life (QOL) was seen with eculizumab treatment. ${ }^{30}$ Quality of life started improving after 1 week in the first trial and 3 weeks in the second trial, and was maintained over the 2 years of treatment. ${ }^{31}$

The dosing of eculizumab was designed to achieve a minimum blood concentration of $50-100 \mu \mathrm{g} / \mathrm{mL}$ to ensure complete complement blockade and to provide sustained low levels of free C5 and high levels of C5 cleavage suppression. ${ }^{30}$ A biomarker of terminal complement activity remained inhibited over 2 years in both studies, ${ }^{31}$ as measured by a modified $\mathrm{CH} 50$ assay (method not described).

\section{Open-label, single-group, multicenter, multinational clinical trial in adult patients}

This clinical trial, performed after those discussed ${ }^{30,31}$ and registered at www.clinicaltrials.gov as NCT01194973, ${ }^{32}$ was conducted in adult patients with aHUS. This was a 26-week, open-label, nonrandomized, single-group, multicenter trial of eculizumab in patients with aHUS in which patients could continue to receive eculizumab in an extension phase. Adult patients ( $\geq 18$ years of age) with a diagnosis of aHUS were enrolled at 23 centers in North America and Europe. Eligible patients had platelet counts $<150 \times 10^{9} / \mathrm{L}$, hemoglobin levels $\leq$ the lower limit of the normal range, LDH levels $\geq 1.5$ times above ULN, serum creatinine levels at or above ULN at screening, ADAMTS13 activity $\geq 5 \%$, and no positive shigatoxin-producing Escherichia coli test. An identified complement gene mutation, associated polymorphism, or factor $\mathrm{H}$ autoantibody was not required. Patients were categorized according to whether they received PE/PI or not during the pretreatment period, defined as beginning on the start date of the current aHUS manifestation up to the first dose of eculizumab.

Forty-one adult patients with aHUS were treated; 38 (93\%) completed the initial 26-week clinical study period and $21(51 \%)$ continued treatment of 1 year during the optional extension period. Twenty patients (49\%) had one or multiple identified mutations in complement genes and/or anti-factor $\mathrm{H}$ antibody. Thirty patients (73\%) were enrolled during their first identified clinical TMA manifestation. At screening, the mean (SD) platelet count was $119.1(66.1) \times 10^{9} / \mathrm{L}$, mean haptoglobin was $0.6(0.4) \mathrm{g} / \mathrm{L}$, and mean LDH level was 492.9 (500.9) U/L. Thirty-five patients $(85 \%)$ received $\mathrm{PE} / \mathrm{PI}$ before eculizumab (mean, 9.6 sessions; range, 1-26) during the pretreatment period. Twenty-four patients $(59 \%)$ were receiving dialysis at 
baseline, and nine $(22 \%)$ had a history of prior renal transplantation. Thirty-three patients $(80 \%)$ had chronic kidney disease stage 4 or 5 (eGFR $\left.<30 \mathrm{~mL} / \mathrm{min} / 1.73 \mathrm{~m}^{2}\right)$.

A prespecified exploratory analysis ${ }^{33}$ was conducted as part of the trial to investigate the effect of terminal complement blockade on several biological markers associated with proximal and terminal complement overstimulation, inflammation, damage of endothelial cells, and coagulation markers, in addition to kidney injury, in patients with aHUS. Various biomarkers (plasma complement Ba, serum soluble tumor necrosis factor receptor-1 [sTNFR1], plasma prothrombin fragment 112 [F112], plasma thrombomodulin, urinary cystatin $\mathrm{C}$, tissue inhibitor of metalloproteinases-1, b2-microglobulin [b2-M], liver fatty acid binding protein [L-FABP-1], creatinine, sC5b-9, and C5a) were used in this study, from either serum, ethylenediaminetetraacetic acid plasma, or urine samples obtained from patients with aHUS at baseline, before eculizumab treatment, and at weeks 1-3, 4-6, 12-17, 26-33, 38-42, and 49-54 during eculizumab treatment. Levels of plasma and serum markers were evaluated from healthy volunteers and patients with aHUS at baseline and at regular intervals during eculizumab treatment over the course of a 1-year period; markers in urine were evaluated over the course of 26 weeks of eculizumab treatment.

At baseline, all biomarkers were elevated significantly in the majority of patients with aHUS compared to levels measured in adult healthy volunteers; $69 \%-83 \%$ of patients with aHUS also showed significantly elevated levels of candidate renal injury biomarkers (ninefold to 48-fold higher than levels measured in healthy people). Levels of these biological markers were increased in patients who presented hematologic improvement from screening to the first dose of eculizumab, including those patients receiving plasma therapy. ${ }^{33}$

Eculizumab treatment reduced terminal complement activation (C5a and sC5b-9) and selected renal injury markers (clusterin, cystatin-C, b2-M, and L-FABP-1) to levels observed in the healthy volunteers. It also significantly reduced inflammation (sTNFR1), coagulation (prothrombin F112 and D-dimer), and endothelial damage (thrombomodulin) biomarkers compared to pretreatment levels (and frequently to levels seen in healthy individuals). Although AP activation and endothelial activation markers decreased, their mean levels were still elevated compared to healthy volunteers. This may reflect persistent complement activation in aHUS, even though terminal complement blockade with eculizumab was achieved. ${ }^{33}$ There were no differences in biomarker assessment between patients who were or were not treated with plasma therapy before enrollment. Unfortunately, controls consisting of patients with similar degrees of chronic kidney disease but without aHUS were not studied, so the meaning of the changes must be interpreted cautiously. At present, there is no uniformly agreed-upon biomarker of either disease activity or response to eculizumab.

\section{Anecdotal case reports of use of eculizumab in patients with aHUS}

Tables $2^{34-49}$ and $3^{22,50-78}$ present the case reports of adult and pediatric patients with aHUS who received eculizumab according to the current label-approved schedule. We were able to find that 39 adults and 38 children were treated in the absence of a clinical trial in the published literature. Overall hematologic and kidney responses to eculizumab, as defined and judged by the authors of the case reports, were $90 \%$ and $56 \%$ for adults, respectively, and $100 \%$ both hematologic and kidney response in children receiving eculizumab. Where applicable, we describe the precipitating factor of ongoing TMA, herein termed the "complement-amplifying condition." The reports in which eculizumab was used for diseases other than aHUS are not mentioned in this review. The reports in which eculizumab was used in a non-FDA-approved dosing schedule are mentioned in Table 4.

\section{Eculizumab and kidney transplantation}

Recent studies have shown that the risk of post-transplant recurrence of aHUS is linked to the underlying genetic abnormality. ${ }^{79,80}$ Higher risks are seen in patients with mutations in circulating complement proteins and regulators genes, in contrast to patients with mutations in $M C P$ (CD-46) who generally, but not always (such as when the MCP mutation is combined with another mutation or highrisk polymorphism), achieve a good kidney transplant outcome. Recurrence of aHUS is shown to have dismal graft survival, ${ }^{80}$ and led to the recommendation, therefore, in the pre-eculizumab era, that isolated renal transplantation was contraindicated in aHUS patients. Combined kidney-liver transplantation and prophylactic PE have been used to prevent post-transplant recurrences with variable outcomes. ${ }^{81}$ More recently, evidence on the benefits of eculizumab in the prevention and treatment of aHUS recurrence has been demonstrated (Table 4).

\section{Retrospective, multicenter review of eculizumab use in renal transplant recipients}

Zuber et al conducted a retrospective, multicenter study to assess eculizumab for the prevention or treatment of posttransplant manifestations in patients with aHUS. ${ }^{79,82}$ From the 22 patients included in the study, 13 patients were enrolled 
Table 2 Anecdotal case reports using eculizumab in aHUS in adults

\begin{tabular}{|c|c|c|c|}
\hline $\begin{array}{l}\text { Author } \\
\text { (year) }\end{array}$ & $\begin{array}{l}\text { Population and } \\
\text { complement-amplifying } \\
\text { condition }\end{array}$ & $\begin{array}{l}\text { Number of } \\
\text { patients } \\
\text { treated with } \\
\text { eculizumab }\end{array}$ & Outcome with eculizumab \\
\hline $\begin{array}{l}\text { Sevinc et al } \\
(2015)^{46}\end{array}$ & $\begin{array}{l}\text { Woman aged } 32 \text { years with plasma-resistant aHUS } \\
\text { and infection }\end{array}$ & 1 & $\begin{array}{l}\text { Hematologic recovery; stopped dialysis } \\
\text { after } 3 \text { months }\end{array}$ \\
\hline $\begin{array}{l}\text { Thajudeen et al } \\
(2013)^{47}\end{array}$ & $\begin{array}{l}\text { Man aged } 5 \mathrm{I} \text { years with eculizumab first-line treatment } \\
\text { and trauma }\end{array}$ & 1 & $\begin{array}{l}\text { Hematologic recovery; stopped dialysis } \\
\text { after } 2.5 \text { months }\end{array}$ \\
\hline $\begin{array}{l}\text { Sengul Samanci et al } \\
(2015)^{45}\end{array}$ & $\begin{array}{l}\text { Man aged } 5 \mathrm{I} \text { years with plasma-resistant aHUS and } \\
\text { severe hypertension }\end{array}$ & 1 & $\begin{array}{l}\text { Hematologic recovery; remained dialysis } \\
\text { dependent }\end{array}$ \\
\hline $\begin{array}{l}\text { Rafiq et al } \\
(2015)^{42}\end{array}$ & $\begin{array}{l}\text { Woman aged } 59 \text { years with recurrent TMA and } \\
\text { accelerated hypertension/illicit drug use }\end{array}$ & 1 & Noncompliant and lost to follow-up \\
\hline $\begin{array}{l}\text { Nguyen et al } \\
(2014)^{39}\end{array}$ & $\begin{array}{l}\text { Man aged } 62 \text { years with CKD3, DM2, and biopsy with } \\
\text { IgA vasculitis relapse of TMA despite I } 4 \text { days of PE } \\
\text { and I month of rituximab }\end{array}$ & 1 & $\begin{array}{l}\text { Hematologic recovery; remained dialysis } \\
\text { dependent }\end{array}$ \\
\hline $\begin{array}{l}\text { Rigothier et al } \\
(2015)^{43}\end{array}$ & Adult with distal angiopathy and ESRD & 1 & $\begin{array}{l}\text { Remission of distal angiopathy; } \\
\text { hematologic recovery; successful kidney } \\
\text { transplantation }\end{array}$ \\
\hline $\begin{array}{l}\text { Ohanian et al } \\
(2011)^{40}\end{array}$ & $\begin{array}{l}\text { Woman aged } 50 \text { years with ischemic colitis and } \\
\text { neurologic impairment }\end{array}$ & 1 & $\begin{array}{l}\text { Renal and neurologic improvement after } \\
\text { third dose; hematologic improvement } \\
\text { after sixth dose }\end{array}$ \\
\hline $\begin{array}{l}\text { Salem et al } \\
(2013)^{44}\end{array}$ & $\begin{array}{l}\text { Woman aged } 66 \text { years with shigatoxin-negative } \\
\text { bloody diarrhea, seizures, and coma }\end{array}$ & 1 & $\begin{array}{l}\text { Stopped dialysis after third dose; } \\
\text { neurologic recovery at week } 7\end{array}$ \\
\hline $\begin{array}{l}\text { Povey et al } \\
(2014)^{41}\end{array}$ & $\begin{array}{l}\text { Woman aged } 2 \mathrm{I} \text { years with neurologic } \\
\text { involvement (PRES) and past history of TMA }\end{array}$ & 1 & $\begin{array}{l}\text { Neurologic and hematologic recovery; } \\
\text { stopped dialysis after } 3.5 \text { months }\end{array}$ \\
\hline $\begin{array}{l}\text { David et al } \\
(20 \mid 3)^{36}\end{array}$ & $\begin{array}{l}\text { Woman aged } 23 \text { years with SRD and TMA unresponsive } \\
\text { to PE and steroids and third trimester of pregnancy }\end{array}$ & 1 & $\begin{array}{l}\text { Hematologic and kidney recovery; } \\
\text { complete resolution of SRD, and eyes } \\
\text { remained stable at 2-month follow-up }\end{array}$ \\
\hline $\begin{array}{l}\text { Ardissino et al } \\
(2013)^{34} \\
\text { Mussoni et al } \\
(2014)^{38}\end{array}$ & $\begin{array}{l}\text { Woman aged } 26 \text { years with relapse of TMA after } \\
39 \text { sessions of PE during pregnancy and strong family } \\
\text { history of aHUS }\end{array}$ & 1 & $\begin{array}{l}\text { Eculizumab infused at } 26 \text { th week of } \\
\text { pregnancy with hematologic and } \\
\text { kidney recovery; patient delivered } \\
\text { a healthy baby girl at } 38 \text { th week with } \\
\text { no signs of TMA }\end{array}$ \\
\hline $\begin{array}{l}\text { Zschiedrich et al } \\
(2013)^{49}\end{array}$ & $\begin{array}{l}\text { Woman aged } 3 \text { I years with plasma-resistant } \\
\text { postpartum aHUS }\end{array}$ & I & $\begin{array}{l}\text { Eculizumab started at day } 18 \text { after } \\
\text { diagnosis with full clinical resolution and } \\
\text { creatinine } 1.0 \mathrm{mg} / \mathrm{dL}\end{array}$ \\
\hline $\begin{array}{l}\text { Tsai and Kuo } \\
(20 \mid 4)^{48}\end{array}$ & $\begin{array}{l}\text { aHUS was defined by MAHA, thrombocytopenia, } \\
\text { and renal failure with plasma ADAMTSI } 3 \text { activity } \\
>10 \% \text {. Other causes of the syndrome of MAHA and } \\
\text { thrombocytopenia, such as DIC, systemic autoimmune } \\
\text { disorders, lupus anticoagulants, metastatic neoplasms, } \\
\text { shigatoxin, or neuraminidase-associated HUS, were } \\
\text { excluded } \\
\text { Case I: patient presented with bloody diarrhea negative } \\
\text { for shigatoxins } \\
\text { Case 2: patient presented } 3 \text { months after undergoing } \\
\text { autologous HSCT for advanced multiple myeloma } \\
\text { Case 3: patient had recurrent episodes of severe } \\
\text { hypertension accompanied by mild renal insufficiency } \\
\text { and MAHA for } 4.5 \text { years before he was found to have } \\
\text { aHUS } \\
\text { Case } 4 \text { : patient presented at } 22 \text { weeks of her third } \\
\text { pregnancy and was initially assumed to have preeclampsia; } \\
\text { however, her disease persisted after termination of } \\
\text { pregnancy } \\
\text { Case 5: patient had kidney biopsy performed for renal } \\
\text { failure at } 3 \text { weeks after her seventh triweekly course } \\
\text { of chemotherapy with gemcitabine and carboplatin for } \\
\text { metastatic cholangiocarcinoma }\end{array}$ & 5 & $\begin{array}{l}\text { After eculizumab infusion, platelet count } \\
\text { began to exhibit steady increase within } \\
3 \text { days in each of the } 5 \text { courses in cases I-4 } \\
\text { No increase in platelet count occurred in } \\
\text { case } 5 \text { while she was being treated with } \\
\text { eculizumab } \\
\text { LDH normalized by day I } 4 \text { in cases } 3 \text { and } 4 \\
\text { and by day } 70 \text { in case } 2 \text {; it did not normalize } \\
\text { by day } 2 \text { I in case I and by day } 84 \text { in case } 5 \\
\text { Improvement of renal function by I stage } \\
\text { was observed: } \\
\text { By day I } 4 \text { in case } 4 \\
\text { By day } 63 \text { in case } 3 \\
\text { By day } 378 \text { in case } 2 \text { (with further } \\
\text { improvement by I stage by day 483) }\end{array}$ \\
\hline
\end{tabular}


Table 2 (Continued)

\begin{tabular}{|c|c|c|c|}
\hline $\begin{array}{l}\text { Author } \\
\text { (year) }\end{array}$ & $\begin{array}{l}\text { Population and } \\
\text { complement-amplifying } \\
\text { condition }\end{array}$ & $\begin{array}{l}\text { Number of } \\
\text { patients } \\
\text { treated with } \\
\text { eculizumab }\end{array}$ & Outcome with eculizumab \\
\hline $\begin{array}{l}\text { Fakhouri et al } \\
(20 \mid 4)^{37}\end{array}$ & $\begin{array}{l}\text { I9 patients who had received four or more weekly } \\
900 \mathrm{mg} \text { infusions of eculizumab were identified through } \\
\text { a query sent to all nephrology centers in France } \\
\text { aHUS was defined as three or more of the following: } \\
\text { acute kidney injury (serum creatinine }>1.4 \mathrm{mg} / \mathrm{dL} \\
\text { [1 } 20 \mu \mathrm{mol} / \mathrm{L}] \text { ), mechanical hemolytic anemia, } \\
\text { thrombocytopenia, and the presence of TMA features } \\
\text { in a kidney biopsy specimen } \\
\text { For first-line therapy, } 16 \text { patients underwent plasma } \\
\text { exchange and } 3 \text { patients received eculizumab }\end{array}$ & 19 & $\begin{array}{l}\text { Median time between aHUS onset and } \\
\text { eculizumab therapy initiation was } 6 \text { days } \\
\text { (range, I-60 days), and median time to } \\
\text { platelet count normalization after } \\
\text { eculizumab therapy initiation was } 6 \text { days } \\
\text { (range, } 2-42 \text { days). At the 3-month } \\
\text { follow-up, } 4 \text { patients still required dialysis, } \\
8 \text { had non-dialysis-dependent CKD, and } \\
7 \text { had normalized kidney function. At last } \\
\text { follow-up (range, } 4-22 \text { months), } \\
3 \text { patients remained dialysis dependent, } \\
7 \text { had nondialysis-dependent CKD } \\
\text { (estimated glomerular filtration rate, } \\
\text { I7-55 mL/min/I. } 73 \text { m²), and } 9 \text { had normal } \\
\text { kidney function. Risks of reaching end-stage } \\
\text { renal disease within } 3 \text { months and I year } \\
\text { of aHUS onset were reduced by half in } \\
\text { eculizumab-treated patients compared with } \\
\text { recent historical controls }\end{array}$ \\
\hline $\begin{array}{l}\text { Ardissino et al } \\
(2014)^{35}\end{array}$ & $\begin{array}{l}\text { Three cases of patients with aHUS and CKD } \\
\text { (case } 3 \text { post-kidney transplant) who developed skin } \\
\text { lesions that completely recovered when disease-specific } \\
\text { treatment was established } \\
\text { One patient responded to plasma therapy, and } 2 \text { also } \\
\text { received eculizumab }\end{array}$ & 2 & $\begin{array}{l}\text { Complete recovery of active skin lesions } \\
\text { and hematologic parameters after } \\
\text { eculizumab treatment }\end{array}$ \\
\hline
\end{tabular}

Abbreviations: ADAMTSI3, a disintegrin and metalloproteinase with a thrombospondin type I motif, member 13; aHUS, atypical hemolytic uremic syndrome; CKD, chronic kidney disease; CKD3, chronic kidney disease stage 3; DIC, disseminated intravascular coagulation; DM2, type 2 diabetes mellitus; ESRD, end-stage renal disease; HSCT, hematopoietic stem cell therapy; HUS, hemolytic uremic syndrome; IgA, immunoglobulin A; LDH, lactate dehydrogenase; MAHA, microangiopathic hemolytic anemia; $\mathrm{PE}$, plasma exchange; PRES, posterior reversible encephalopathy syndrome; SRD, serous retinal detachment; TMA, thrombotic microangiopathy.

in Europe ${ }^{82}$ and nine were reviewed from the published literature. ${ }^{83-85}$ Cases were reported in two groups: 1) patients who received eculizumab prior to transplantation to prevent subsequent TMA manifestations $(\mathrm{n}=9)$; and 2) patients who received eculizumab to treat post-transplant aHUS manifestations $(n=13)$. Individual patient information describing eculizumab use prior to the transplantation is included in Table $4 .{ }^{52,53,73,79,82,86-98}$

\section{Use of eculizumab prior to transplantation $(n=9)$}

Nine patients received eculizumab prior to transplantation to prevent post-transplant aHUS manifestations and allograft loss. Five patients had heterozygous mutations in $\mathrm{CFH}$, three had a large $C F H / C F H R 1$ nonhomologous recombination, and one had a gain-of-function C3 mutation. Three patients had received four kidney transplants, all lost to post-transplant aHUS manifestations. Median age at time of present transplant was 9 years (range, 6.4-41.0 years). Two patients had preformed donor-specific antibodies with low titer (mean fluorescence intensity $<1,000$ ) at the time of transplantation. Strategy around the use of eculizumab consisted of one of the following three methods: 1) PE started just before transplantation, then switched to eculizumab after transplantation $(n=2)$; 2) eculizumab initiated 1 week or more before transplantation $(n=2)$; and 3 ) eculizumab initiated $\leq 24$ hours before transplantation with additional dose immediately before $(n=1)$ or within 24 hours after $(n=4)$ transplantation. Eight of nine patients treated with eculizumab maintained allograft function and experienced no additional post-transplant aHUS manifestations from 2-39 months of follow-up (mean 14.5 months). One allograft (case \#8, Zuber et $\mathrm{al}^{82}$ ) was lost to immediate arterial thrombosis, despite undetectable $\mathrm{CH} 50$ activity. This patient was ultimately successfully retransplanted under peritransplant eculizumab therapy. ${ }^{11}$ No significant infectious complications were reported.

\section{Post-transplant treatment of aHUS with eculizumab $(n=13)$}

From the 13 patients who received eculizumab to treat posttransplant aHUS, two received it because of intolerance to plasma therapy or convenience. Ten patients presented with plasma-resistant aHUS. One was treated with complement 
Table 3 Anecdotal case reports of use of eculizumab in children and adolescents with aHUS

\begin{tabular}{lll}
\hline $\begin{array}{l}\text { Author } \\
\text { (year) }\end{array}$ & $\begin{array}{l}\text { Case presentation and } \\
\text { complement-amplifying condition }\end{array}$ & $\begin{array}{l}\text { Number of } \\
\text { patients } \\
\text { treated with } \\
\text { eculizumab }\end{array}$ \\
& & \\
&
\end{tabular}

Diamante Chiodini et al Boy aged 8 years with shigatoxin-negative bloody $(2014)^{60}$

Coppo et al $(2015)^{58}$ diarrhea and severe neurologic impairment

Girl aged 4 years with lupus nephritis resistant to conventional therapy and features of aHUS resistant to plasma therapy
Vaisbich et al

$(2013)^{77}$

Hisano et al

$(2015)^{65}$

Noone et al

$(2012)^{71}$

Cullinan et al

$(2015)^{59}$

Mache et al

$(2009)^{68}$

Belingheri et al $(2014)^{54}$

Christmann et al

$(2014)^{57}$

Dorresteijn et al

$(2012)^{61}$

Bekassy et al $(2013)^{53}$

Hu et al

$(2014)^{66}$

Tschumi et al

$(201 \mathrm{I})^{76}$

Michaux et al $(2014)^{70}$

Ohta et al $(2015)^{72}$
Boy aged I 4 months with aHUS, hypertension, and proteinuria

Boy aged 4 years with aHUS, nonoliguric kidney injury, macrohematuria, and anti-factor $\mathrm{H}$ antibodies

Boy aged I 3 years with post-kidney transplant TMA, AMR, and aHUS

Girl aged 8 months with aHUS and multiple TMA relapses treated with 212 sessions of PE; mother has aHUS

Boy aged 17.8 years with plasma-resistant aHUS

Young male, first presentation at 6 months, remained with CKD until age 7 years, when PI was started because of relapses; remained with CKD, proteinuria, and hypertension

\section{Girl aged 5.5 months with aHUS and severe} hypertension

Girl aged 6 years with aHUS treated initially with PE for 3 weeks, followed by PI; developed relapse during upper respiratory infection, and PE did not improve renal function despite platelet count normalization

Girl aged 12 years with aHUS and kidney failure since age 20 months; bilateral nephrectomy and a lost graft due to aHUS; at 10 years of age, transient ischemic attack and occlusion of carotid arteries

19-month-old girl with severe neurologic involvement and cardiomyopathy

Girl aged 9 years with plasma-dependent aHUS

Neonate aged II days with severe aHUS (myocardial impairment, respiratory failure, acute kidney disease requiring hemodiafiltration) Boy aged 4 months who developed aHUS; repeated plasma infusions and 9 sessions of plasmapheresis were ineffective. The patient initially required continuous hemodiafiltration and thereafter peritoneal dialysis
Eculizumab started on day 37 with complete recovery of neurologic and hematologic parameters and improvement in kidney function (stopped dialysis after first dose)

Prompt remission of vasculitis, proteinuria, and hematuria; normalization of renal function; 2 attempts to withdraw eculizumab followed by severe relapses and rescued by reinstating treatment; received eculizumab treatment for $>17$ months without relevant side effects.

Hematologic improvement; stopped dialysis after second dose of eculizumab

Macrohematuria disappeared after second dose; discharged with complete hematologic and kidney resolution

Kidney function recovery with AMR treatment and eculizumab; graft lost due to BK (polyomavirus) nephropathy

Patient treated with eculizumab for 52 months with complete remission and no relapses

Hematologic recovery and partial kidney function improvement; eculizumab used only on relapses and progressed to ESRD Eculizumab started at age II years with no more relapses; decrease in proteinuria, and no need for dialysis

Hematologic improvement on day 3; stopped dialysis 2 weeks after first dose

Renal function started to improve 48 hours after first eculizumab dose; complete remission achieved until last follow-up 9 months later

Started eculizumab without overt TMA and despite being anephric. She received a successful kidney transplant and did not have progression of carotid lesions

Eculizumab infused 12 hours after admission. Normal echocardiography on day 15, stopped dialysis on day 18 , and was discharged with mild hemiparesis, but completely alert

Eculizumab started on day I26; PE was stopped and there were no relapses in 24 months of follow-up. Mild CKD due to fibrosis

I Early treatment with eculizumab as first-line therapy and completely recovered within 5 days. With $>24$ months of follow-up, renal function remains normal Eculizumab started on day 48 of diagnosis with improvement in hypertension, and dialysis was stopped on day 1I7. CKD2 at 17 months of follow-up 
Table 3 (Continued)

\begin{tabular}{|c|c|c|c|}
\hline $\begin{array}{l}\text { Author } \\
\text { (year) }\end{array}$ & $\begin{array}{l}\text { Case presentation and } \\
\text { complement-amplifying condition }\end{array}$ & $\begin{array}{l}\text { Number of } \\
\text { patients } \\
\text { treated with } \\
\text { eculizumab }\end{array}$ & Outcome with eculizumab \\
\hline $\begin{array}{l}\text { Ariceta et al } \\
(2012)^{51}\end{array}$ & $\begin{array}{l}\text { Boy aged } 28 \text { days with plasma-resistant aHUS. } \\
\text { He developed multiple intestinal perforations } \\
\text { and leg skin necrosis due to systemic TMA }\end{array}$ & I & $\begin{array}{l}\text { Within } 48 \text { hours of first eculizumab infusion, the } \\
\text { patient recovered from acute kidney failure, with } \\
\text { complete hematologic remission } 2 \text { weeks later }\end{array}$ \\
\hline $\begin{array}{l}\text { Al-Akash et al } \\
(20 \mathrm{II})^{50}\end{array}$ & $\begin{array}{l}\text { Boy aged I } 5 \text { years with aHUS since age } \\
16 \text { months, ESRD and two failed kidney } \\
\text { transplants }\end{array}$ & I & $\begin{array}{l}\text { Eculizumab used as rescue of aHUS after the third } \\
\text { kidney transplant with complete recovery of renal } \\
\text { function } 3 \text { weeks after the first dose }\end{array}$ \\
\hline $\begin{array}{l}\text { Roman-Ortiz et al } \\
(2014)^{73}\end{array}$ & $\begin{array}{l}\text { Boy aged } 9 \text { years presented with aHUS at age } 3 \text {; } \\
\text { irreversible renal failure and uncontrolled severe } \\
\text { hypertension with concentric left ventricular } \\
\text { hypertrophy, recurrent acute pulmonary edema, } \\
\text { and congestive heart failure despite } 5 \text { hypotensive } \\
\text { agents and bilateral nephrectomy }\end{array}$ & I & $\begin{array}{l}\text { Kidney transplant performed with prophylactic } \\
\text { eculizumab; after } 3 \text { years of continuous use, } \\
\text { hypertension is controlled, no left ventricular } \\
\text { hypertrophy, no opportunistic infections, and negative } \\
\text { clinical chemistry parameters for hemolysis }\end{array}$ \\
\hline $\begin{array}{l}\text { Cayci et al } \\
(2012)^{56}\end{array}$ & $\begin{array}{l}\text { Girl aged } 10 \text { years with negative-culture bloody } \\
\text { diarrhea and plasma-resistant aHUS }\end{array}$ & I & $\begin{array}{l}\text { Eculizumab started on day } 15 \text { with diuresis } \\
\text { improvement in } 24 \text { hours and complete hematologic } \\
\text { and kidney recovery in } 2 \text { weeks }\end{array}$ \\
\hline $\begin{array}{l}\text { Lapeyraque et al } \\
(2011)^{67}\end{array}$ & $\begin{array}{l}\text { Girl aged } 7 \text { years with aHUS. Weekly PI with } \\
\text { short-term intensified PI during aHUS } \\
\text { exacerbations was effective for } 4.3 \text { years; }\end{array}$ & I & $\begin{array}{l}\text { Eculizumab was started with complete reversal of } \\
\text { TMA after I week; no relapses and normal kidney } \\
\text { function after } 12 \text { months of follow-up }\end{array}$ \\
\hline
\end{tabular}

Vilalta et al

$(2012)^{78}$

Azukaitis et al $(2014)^{52}$

Sharma et al $(2015)^{75}$

Besbas et al $(2013)^{55}$

Giordano et al $(2012)^{62}$

Schalk et al $(2015)^{74}$ progressive mild renal failure (stage 2 ) and aHUS

exacerbation unresponsive to intensified $\mathrm{PI}$

Girl aged 4 years with multiple severe clinical manifestations including acute kidney injury, dilated cardiomyopathy, and cardiorespiratory arrest; intense PE did not halt TMA manifestations

Boy with first manifestation of aHUS at age

2 months and a relapse at age 10 months leading to ESRD despite PI. Remained hypertensive in dialysis and had convulsions at age 5.5 years, when stenosis of left carotid artery and bilateral middle cerebral arteries was diagnosed Girl aged 28 days presented with plasma-resistant I aHUS with gross hematuria and hypertension

Newborn aged 5 days with aHUS and full renal and hematologic remission after PI. The patient was discharged with FFP infusions but subsequently developed 3 life-threatening disease recurrences at I month, 3 months, and 6 months of age. The last relapse presented with uncontrolled hypertension and impaired renal function while the patient was receiving FFP infusions

Boy aged 8 months with aHUS resistant to 2I PI and I5 PE treatments

Boy aged 3 years with aHUS and frequent relapses requiring $\mathrm{PI}$

The initial single dose of eculizumab only temporarily improved the clinical symptoms of TMA; sustained improvement of renal, hematologic, and cardiac values were achieved only upon institution of chronic treatment with eculizumab ( 2.5 years)

At age 6.5 years received a kidney transplant under prophylactic eculizumab with no signs of posttransplant aHUS; evolved with seizures and cerebral ischemia on the fourth postoperative day, leading to death

After I dose of eculizumab, dialysis was discontinued and her hematologic parameters improved; after I I months of follow-up, she remains on eculizumab and penicillin without recurrence of aHUS or any infectious complications

Five days following the first dose of eculizumab, renal and hematologic parameters returned to normal range and blood pressure normalized; FFP infusions were gradually decreased and stopped; at the time of the report, the patient was 20 months of age and currently on eculizumab treatment every other week with completely normal renal and hematologic parameters

Eculizumab first dose at age 12 months with hematologic improvement in I week and dialysis cessation in 5 days; no relapses and no PE/PI needed Started eculizumab and continued presenting relapses despite complement blockade; the authors decided to administer the medication immediately in times of immunologic triggers, such as immunizations or infections; at the time of report, the patient had been in a stable condition with an eGFR of $90 \mathrm{~mL} / \mathrm{min} / 1.73 \mathrm{~m}^{2}$ and no further TMA events for more than a year 
Table 3 (Continued)

\begin{tabular}{|c|c|c|c|}
\hline $\begin{array}{l}\text { Author } \\
\text { (year) }\end{array}$ & $\begin{array}{l}\text { Case presentation and } \\
\text { complement-amplifying condition }\end{array}$ & $\begin{array}{l}\text { Number of } \\
\text { patients } \\
\text { treated with } \\
\text { eculizumab }\end{array}$ & Outcome with eculizumab \\
\hline $\begin{array}{l}\text { Gulleroglu et al } \\
(2013)^{64}\end{array}$ & $\begin{array}{l}\text { Girl aged II years developed aHUS and was } \\
\text { treated immediately with PE/PI. Although initial } \\
\text { improvement in renal function was seen, patient } \\
\text { showed progressing TMA despite daily PE, } \\
\text { and neurologic manifestations developed after } \\
\text { I month } \\
\text { Girl aged } 6 \text { years developed cerebral } \\
\text { TMA (seizures, vision loss, and nystagmus) } 6 \text { days } \\
\text { after initial presentation and remained } \\
\text { unresponsive to PE/PI }\end{array}$ & 2 & $\begin{array}{l}\text { Treatment with eculizumab achieved complete } \\
\text { control of neurologic symptoms within } 24 \text { hours } \\
\text { and gradually normalized hematologic and renal } \\
\text { parameters in both children }\end{array}$ \\
\hline $\begin{array}{l}\text { Malina et al } \\
(2013)^{69}\end{array}$ & $\begin{array}{l}\text { Girl aged } 4 \text { years developed gangrene of the } \\
\text { fingertips } 2 \text { days after initial presentation of aHUS. } \\
\text { Renal function continued to decline despite daily } \\
\text { PE, and she was started on peritoneal dialysis } \\
5 \text { days after admission. The distal tips of the } \\
\text { left hand remained gangrenous with a line of } \\
\text { demarcation. Three weeks later, she did not } \\
\text { return for follow-up and died at home because } \\
\text { of dialysis-related complications }\end{array}$ & I & \\
\hline & $\begin{array}{l}\text { Another girl developed ESRD due to aHUS in } \\
\text { the fourth month after birth. At age } 9 \text { months, } \\
\text { she suddenly developed ischemic changes in } \\
\text { fingers of both hands and several toes. The } \\
\text { lesions progressed, and several fingertips } \\
\text { became gangrenous despite intense PE therapy }\end{array}$ & & $\begin{array}{l}\text { Eculizumab was started on the second case and all } \\
\text { non-necrotic digits rapidly regained perfusion. The } \\
3 \text { already gangrenous fingers healed with loss of the } \\
\text { end phalanges; during maintenance, eculizumab aHUS } \\
\text { activity subsided completely, and some late recovery } \\
\text { of renal function was observed }\end{array}$ \\
\hline $\begin{array}{l}\text { Baskin et al } \\
(2015)^{22}\end{array}$ & $\begin{array}{l}\text { Retrospective analysis of } 15 \text { children diagnosed } \\
\text { with aHUS, which was defined as HUS negative } \\
\text { for STEC } \\
\text { Three patients had relapses, and } 7 \text { had a new } \\
\text { diagnosis. Nine children had oliguria or anuria, } \\
\text { and } 8 \text { required dialysis. Hypertension was }\end{array}$ & 10 & $\begin{array}{l}\text { Ten were resistant to, or dependent on, plasma } \\
\text { therapy and treated with eculizumab; following the } \\
\text { start of eculizumab treatment, all patients achieved } \\
\text { full recovery of renal function and hematologic } \\
\text { parameters. }\end{array}$ \\
\hline
\end{tabular}
and 8 required dialysis. Hypertension was observed in 6 patients. Neurologic involvement developed in 6 patients.

Gruppo and Rother $(2009)^{63}$
Congenital aHUS: first manifestation at 8 days of life treated with $\mathrm{Pl}$; relapses at 3 months, 9 months, and II months of age; all treated with $\mathrm{PI}$ with good response after 2 weeks; fourth relapse at 18 months unresponsive to $\mathrm{PE}$.

\begin{abstract}
Eculizumab was started on the second case and all non-necrotic digits rapidly regained perfusion. The 3 already gangrenous fingers healed with loss of the end phalanges; during maintenance, eculizumab aHUS completely, and some late recovery therapy and treated with eculizumab; following the full recovery of renal function and hematologic
\end{abstract}

Eculizumab was initiated at day 35 of the fourth relapse with improvement in hemolysis in 48 hours and complete remission in 10 days (with no PE/PI)

Abbreviations: aHUS, atypical hemolytic uremic syndrome; AMR, antibody-mediated rejection; CKD, chronic kidney disease; CKD2, chronic kidney disease stage 2; eGFR, estimated glomerular filtration rate; ESRD, end-stage renal disease; FFP, fresh frozen plasma; PE, plasma exchange; PI, plasma infusion; STEC, shigatoxin-producing Escherichia coli; TMA, thrombotic microangiopathy.

blockade as first-line treatment. No mutations were found in two of the 12 patients screened. Overall, there were 17 renal transplants, and 14 had been lost by aHUS recurrence, two by vascular thrombosis, and one by chronic allograft nephropathy. The median interval between renal transplantation and recurrence was 2 months (from 3 days to 5 years). The delay between recurrence and treatment with eculizumab was 30 days (from 1 day to 14 months).

Donor-specific antibodies were not detected in any patient, and histological findings of TMA were present on biopsy in $77 \%$ of patients (of which one only exhibited signs of antibody-mediated rejection). All but three patients were maintained on eculizumab until last follow-up. Two patients who received a single dose of eculizumab presented a relapse after aHUS remission, but this did not resolve with eculizumab reintroduction; the patients progressed to ESRD. In all patients, there was good hematologic response (defined by the authors), as well as kidney function improvement. In the patients unresponsive to plasma therapy, renal function recovery was inversely proportional to the delay in starting eculizumab therapy, as few patients had kidney function benefit when the drug was started after 1 month. 


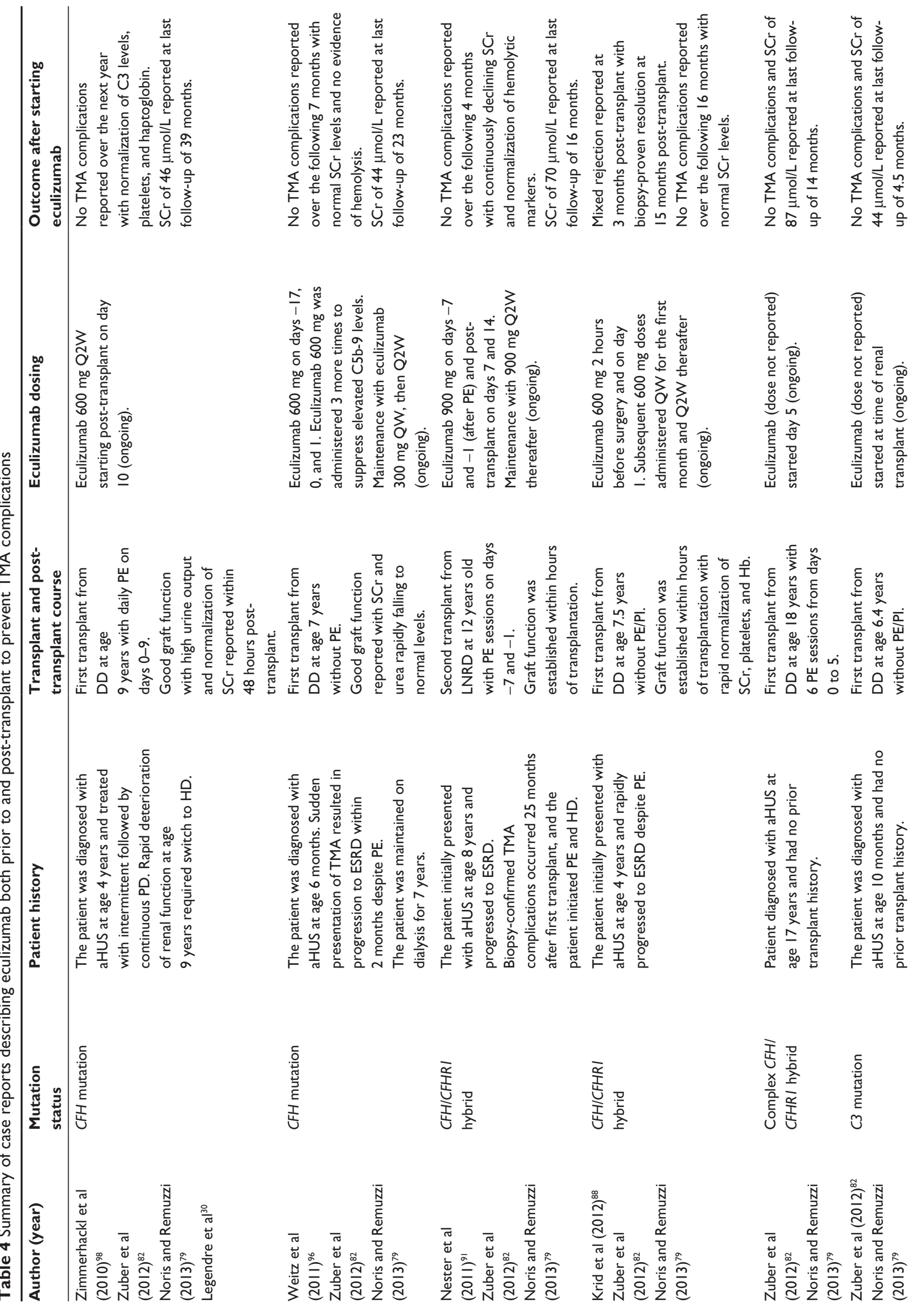



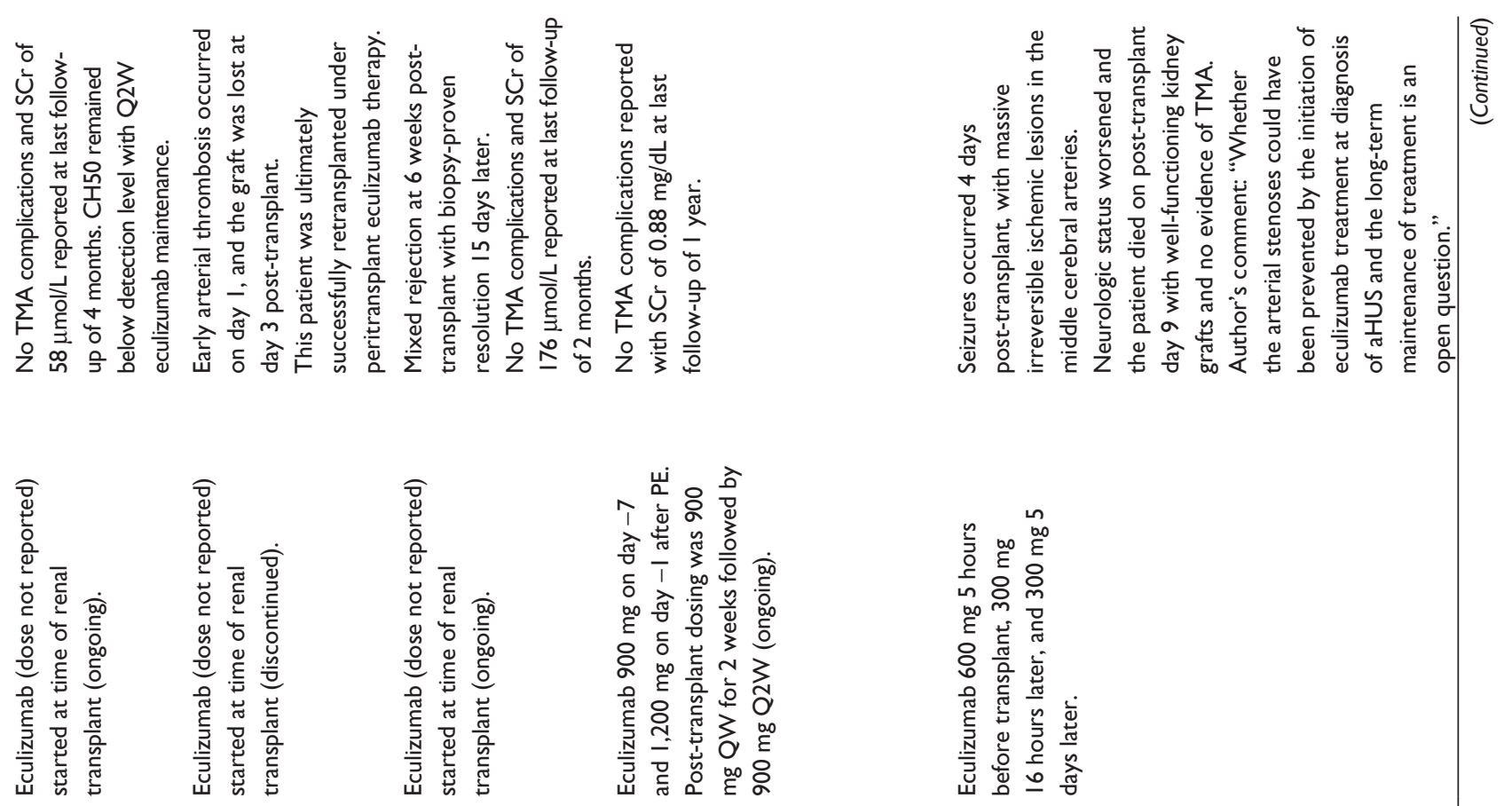

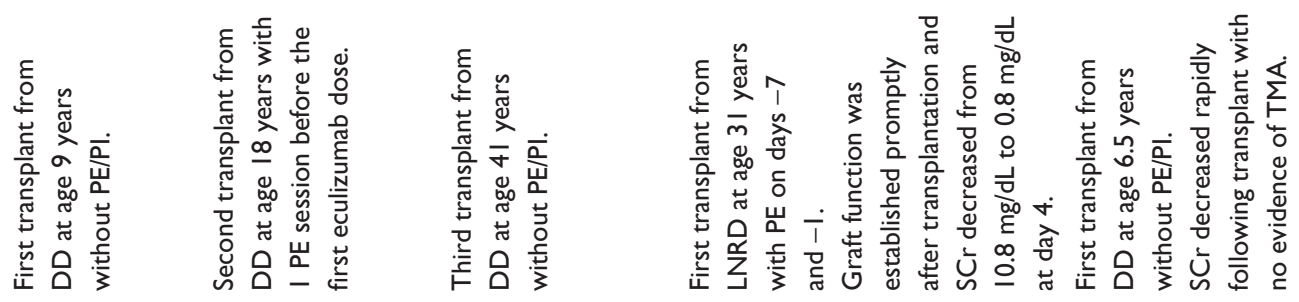
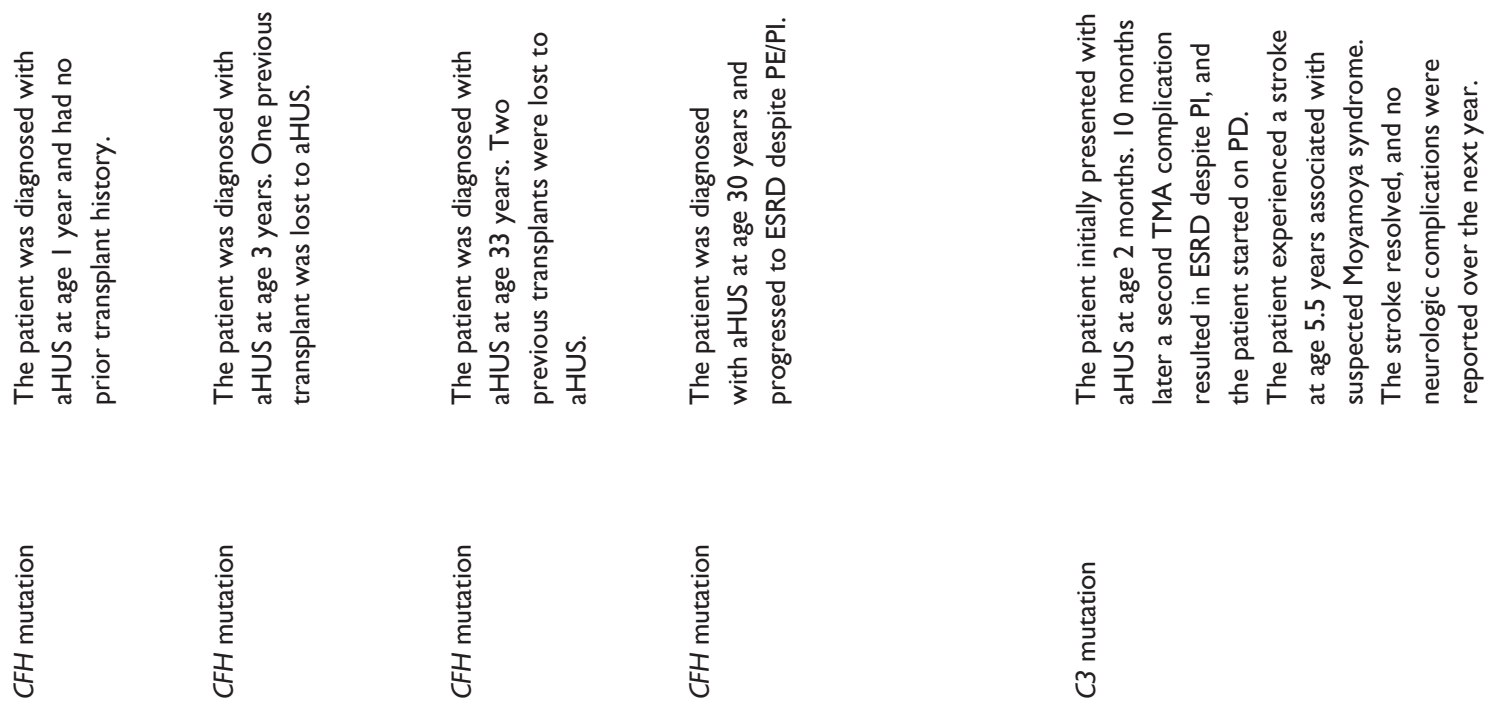

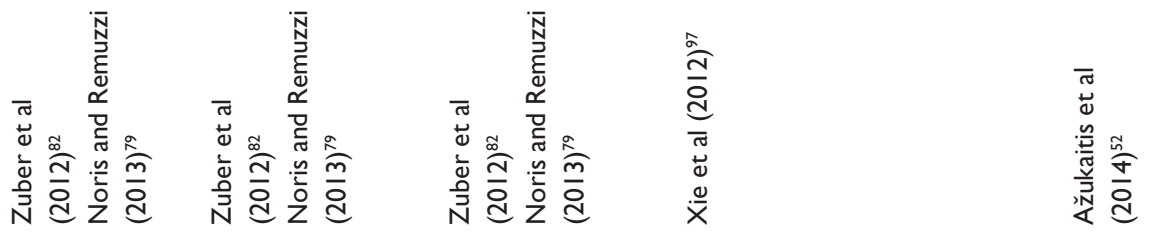




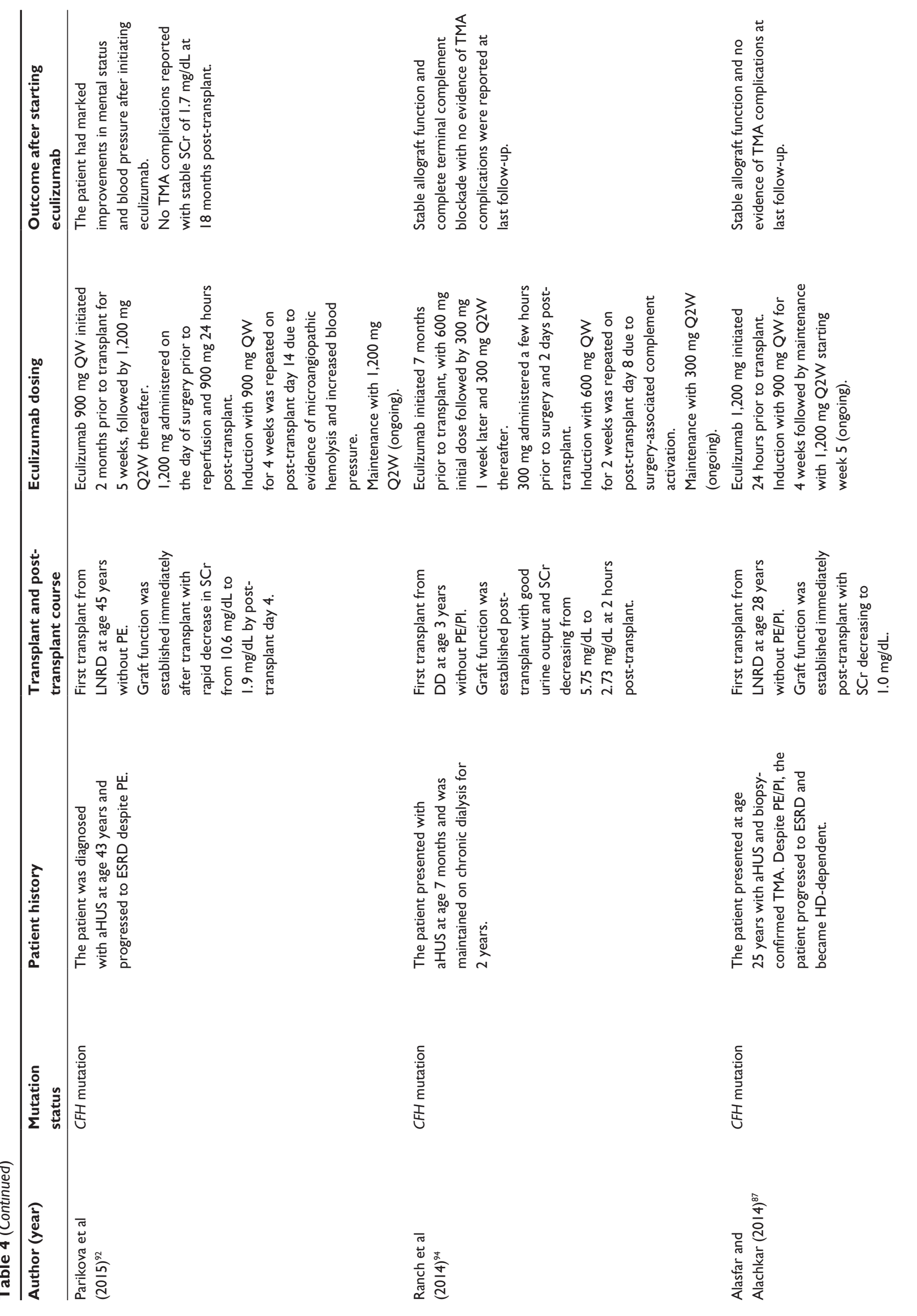



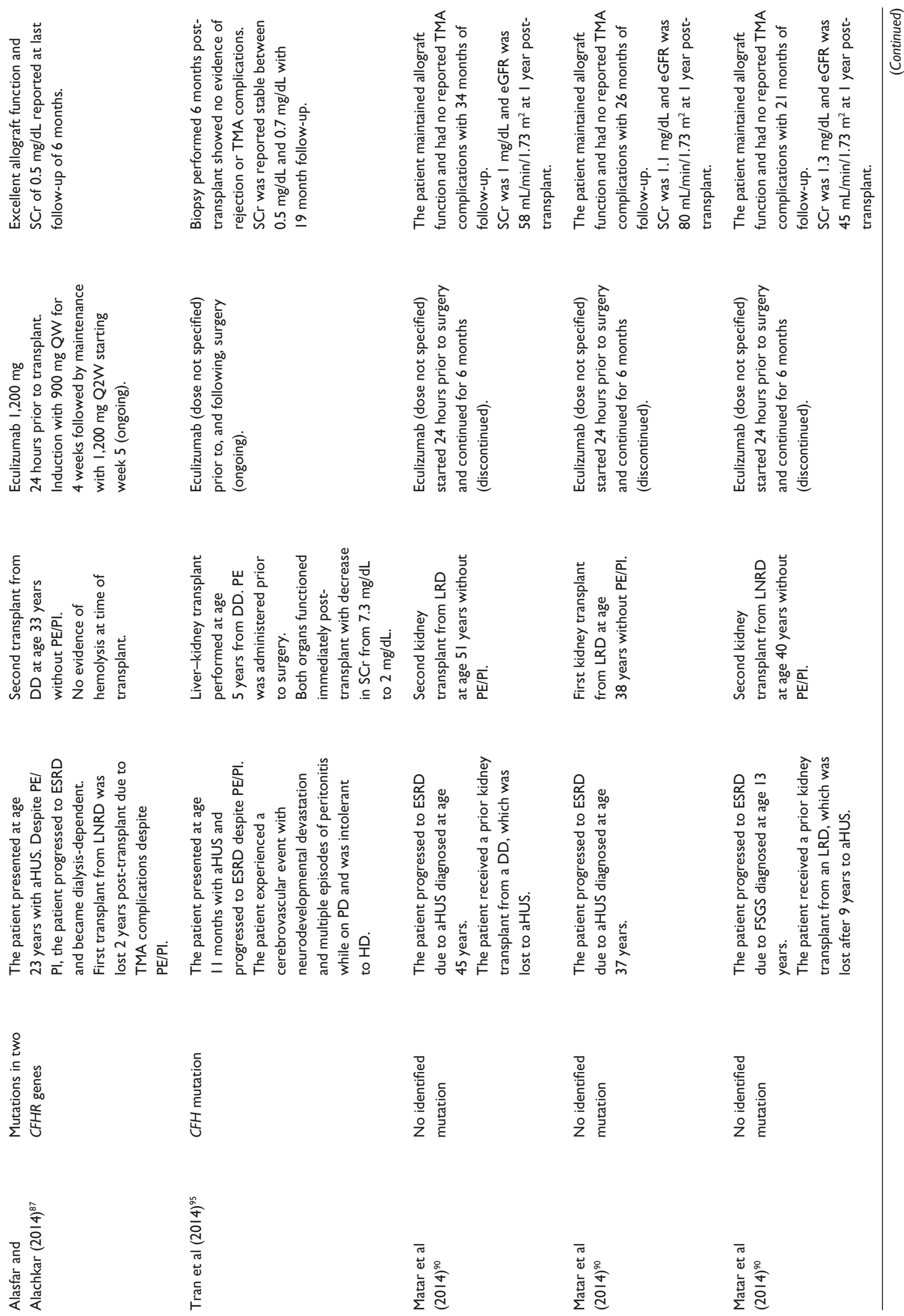


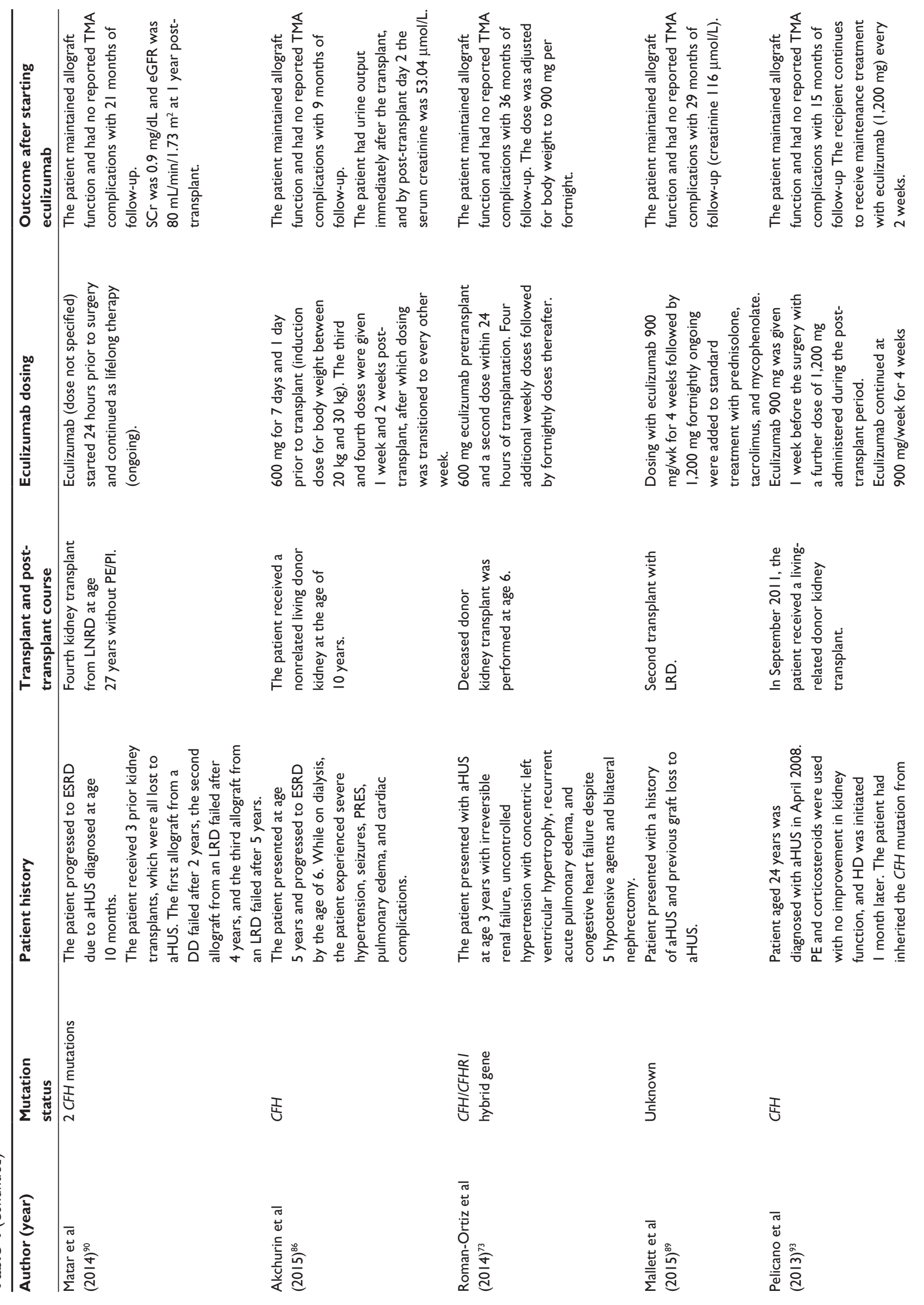



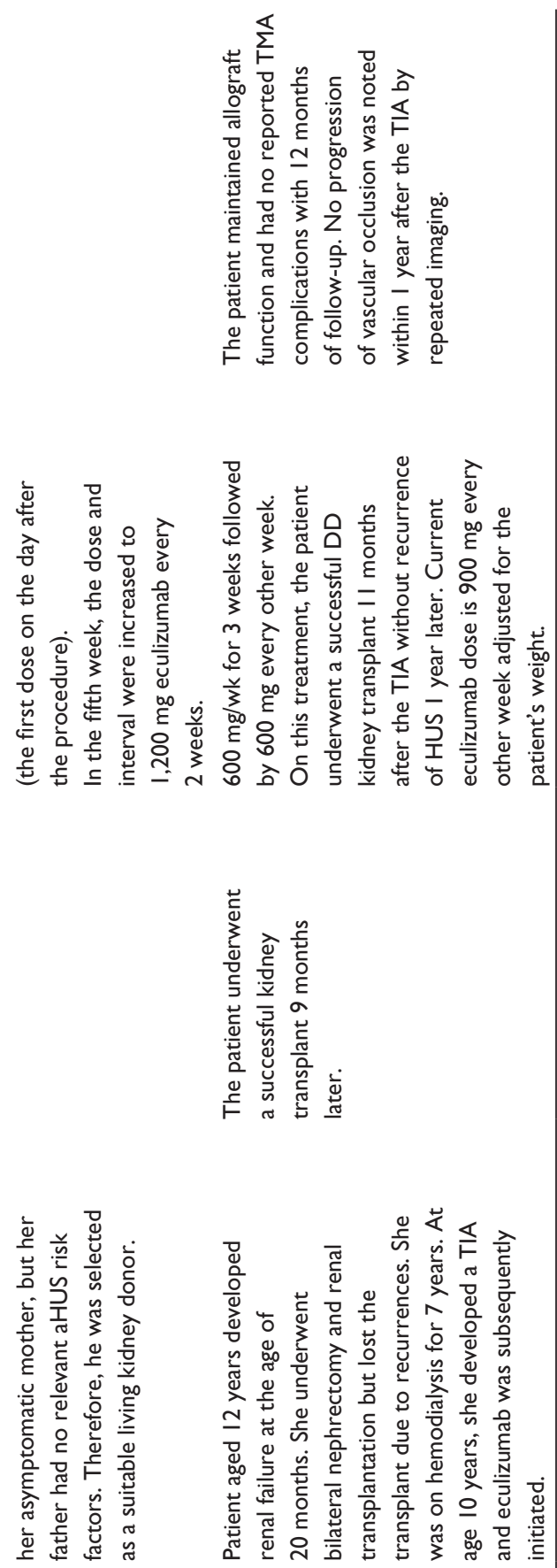

는
운

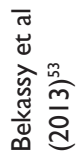

Two patients presented with a pulmonary infection by $M$. tuberculosis and $H$. influenza, respectively, and one patient had hypogammaglobulinemia (history of prior splenectomy and use of rituximab), but good outcome with antibiotics and subcutaneous immunoglobulin.

\section{Retrospective single center case series of eculizumab use in renal transplant recipients}

Matar et $\mathrm{al}^{90}$ reported a retrospective study of 12 consecutive patients with an established diagnosis of aHUS who underwent at least one kidney transplant at a single institution between 2003 and 2013. Diagnosis of primary aHUS was confirmed by evidence of thrombocytopenia, hemolytic anemia, acute renal failure, normal ADAMTS13 levels, and negative for shigatoxin-producing $E$. coli-HUS.

Six patients had an established diagnosis of aHUS as their primary disease prior to their first transplant, three patients were diagnosed with aHUS post-transplant, two patients had an unclear diagnosis as the cause of the primary disease, and one patient was diagnosed with focal segmental glomerular sclerosis as their primary disease. All patients had genetic testing for complement mutations: six patients $(50 \%)$ had identified complement mutations, including four with $\mathrm{CFH}$ mutations, one with an $M C P$ mutation, and one with a $T H B D$ mutation. The 12 patients received a total of 23 kidney transplants. Six patients had only a single transplant, three patients had two transplants each, and three patients had more than two transplants. Four patients considered at high risk of post-transplant TMA complications received eculizumab starting 24 hours prior to transplantation. Individual patient information is included in Table 5. All patients maintained allograft function, and there were no reported TMA complications with 21-34 months of follow-up.

\section{Retrospective, multicenter review of eculizumab use for aHUS in England}

Sheerin et $a{ }^{13}$ reported on the use of eculizumab commissioned by NHS England in 2013 for both new patients with aHUS and long-duration aHUS, including those who underwent renal transplantation. Overall, 43 patients received eculizumab: 15 (35\%) were $<18$ years (eleven male, four female); 28 (65\%) were adults (nine male, 19 female); 23 (53\%) had active progressing TMA, and $20(47 \%)$ had a long duration of aHUS. At the time of publication, 31 (72\%) patients were receiving ongoing eculizumab. Three of 14 (21\%) patients who discontinued eculizumab had subsequent 


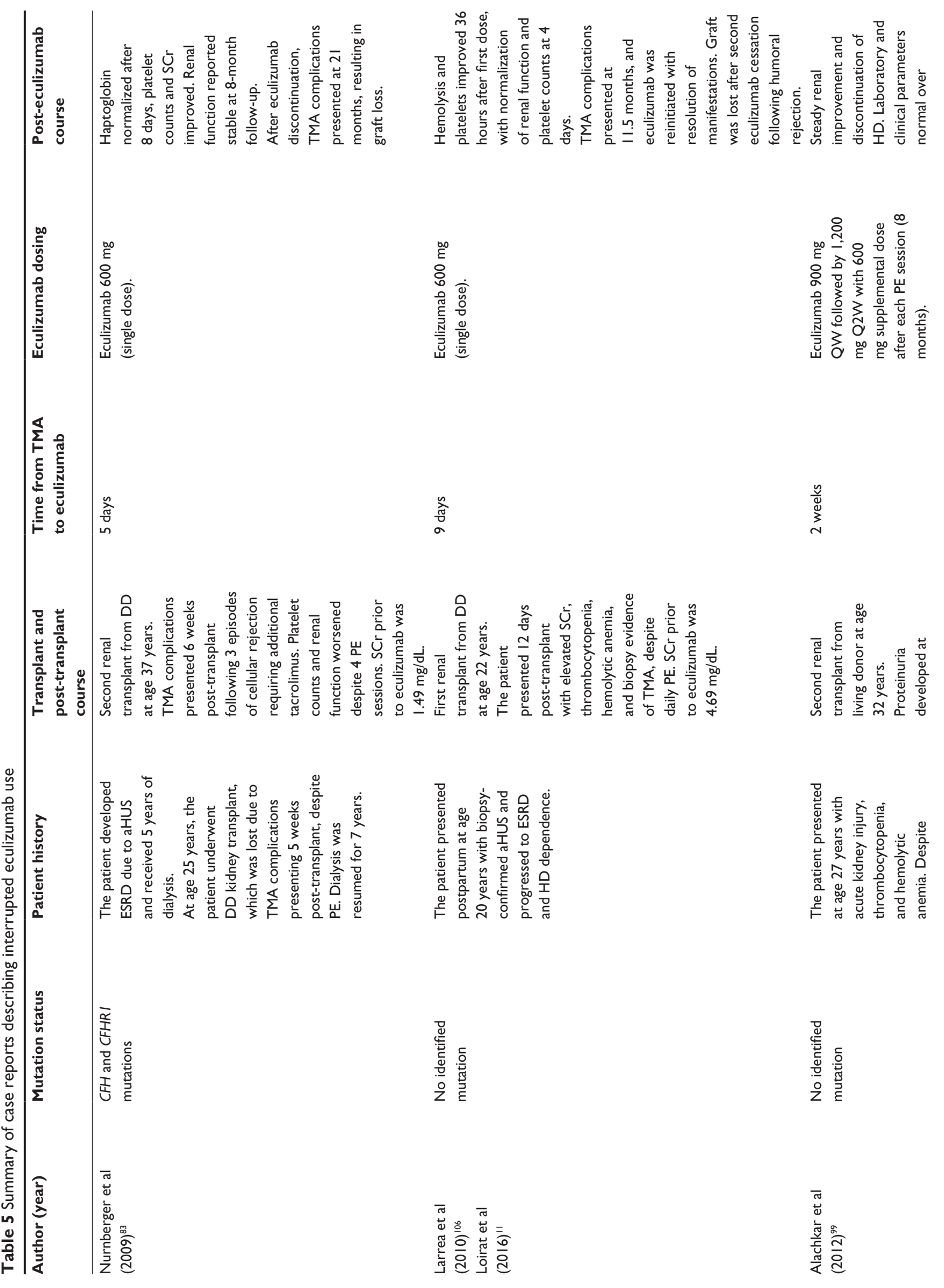



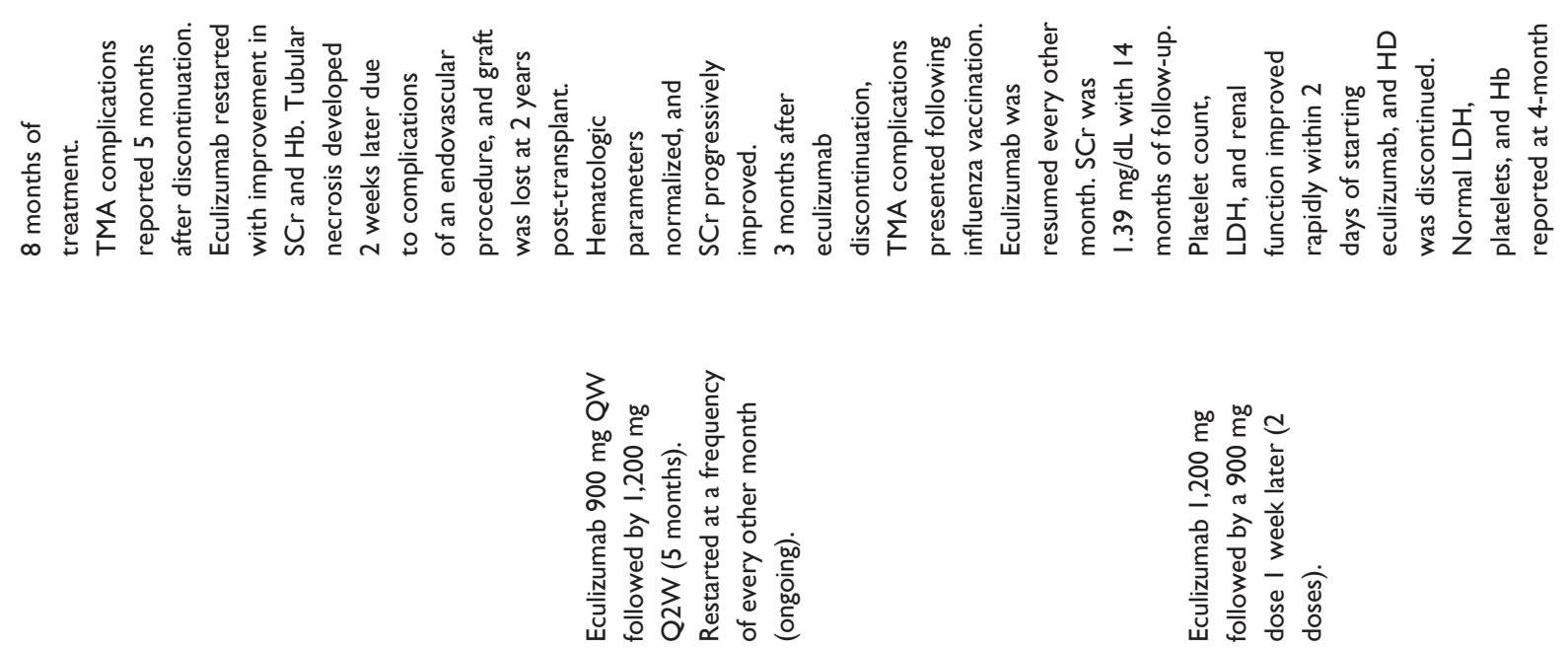

홈

胥

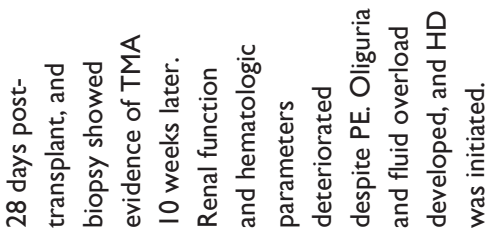
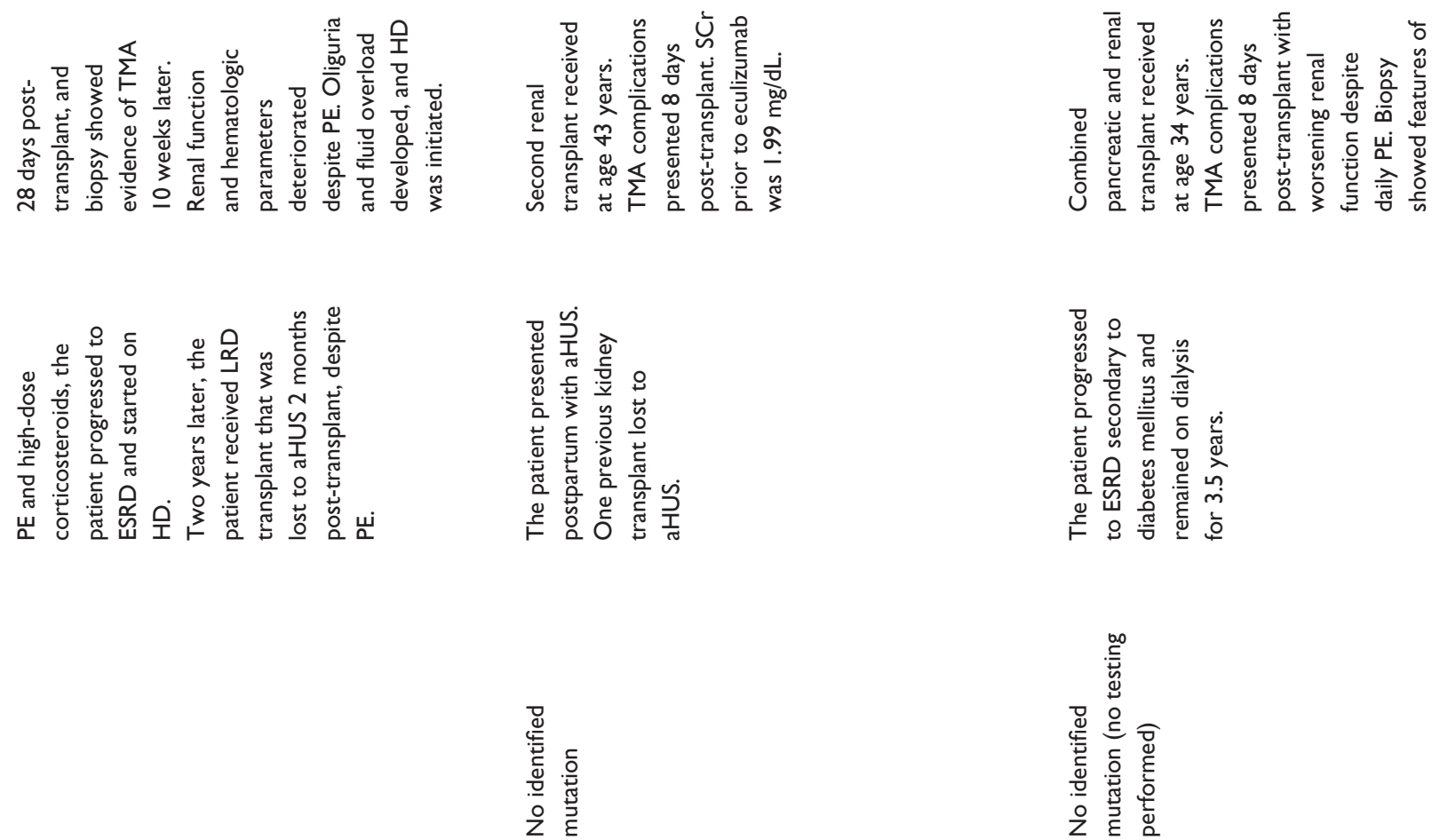

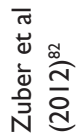

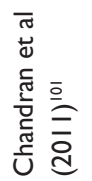




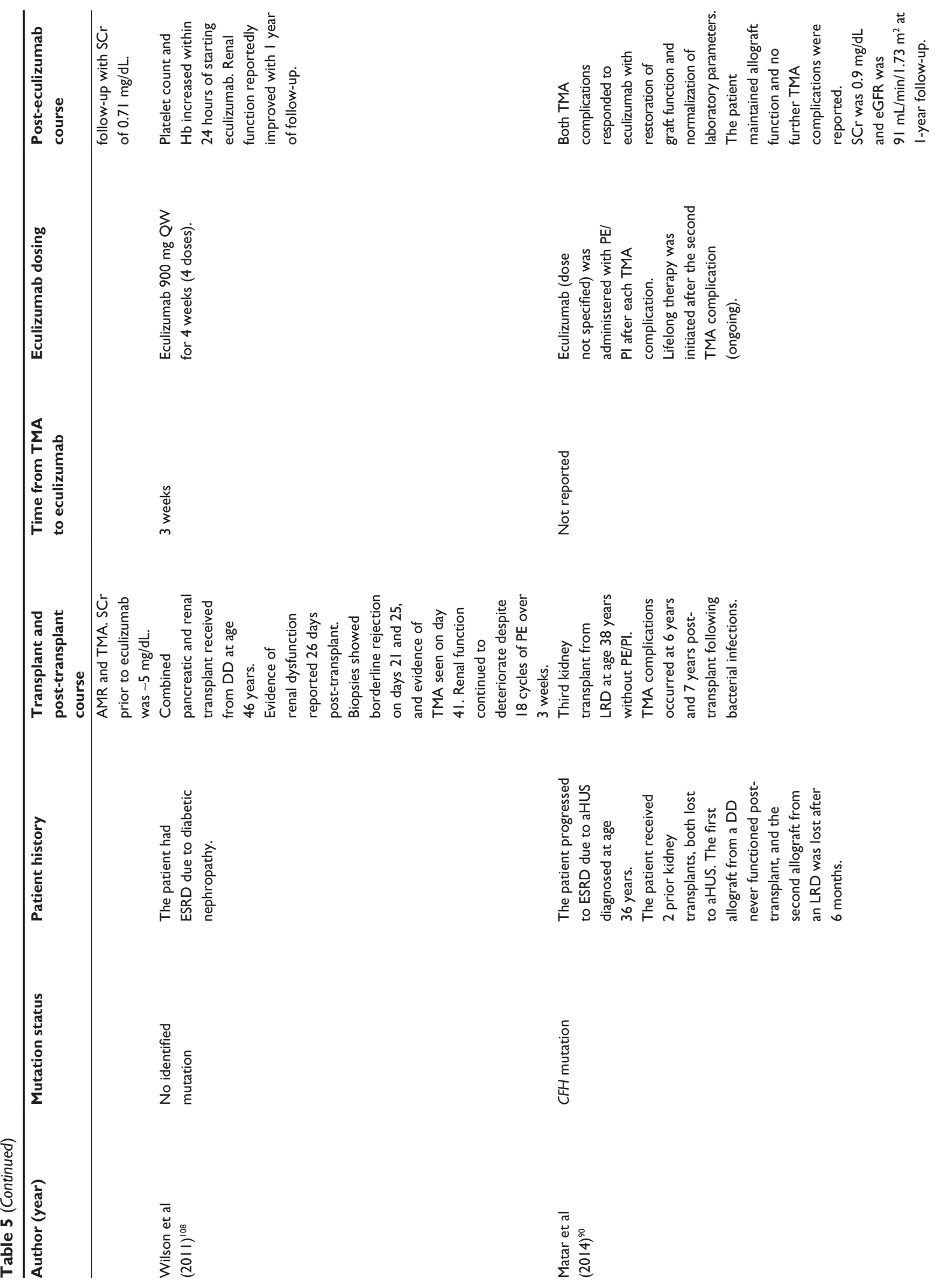



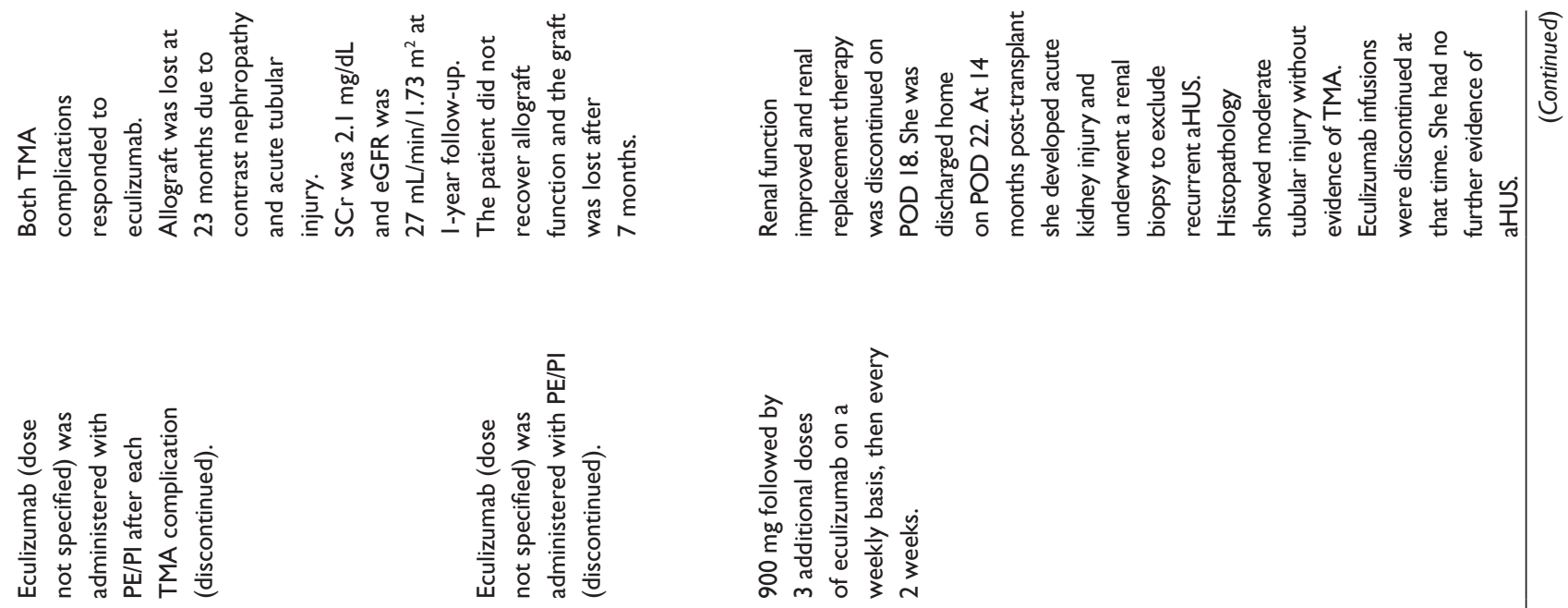

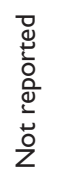

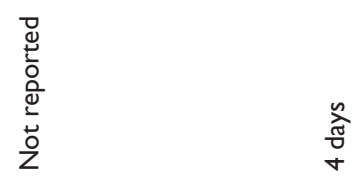

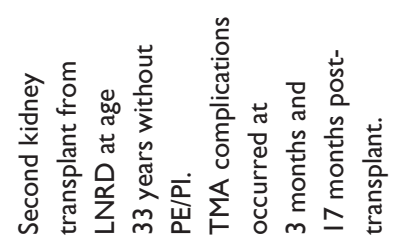
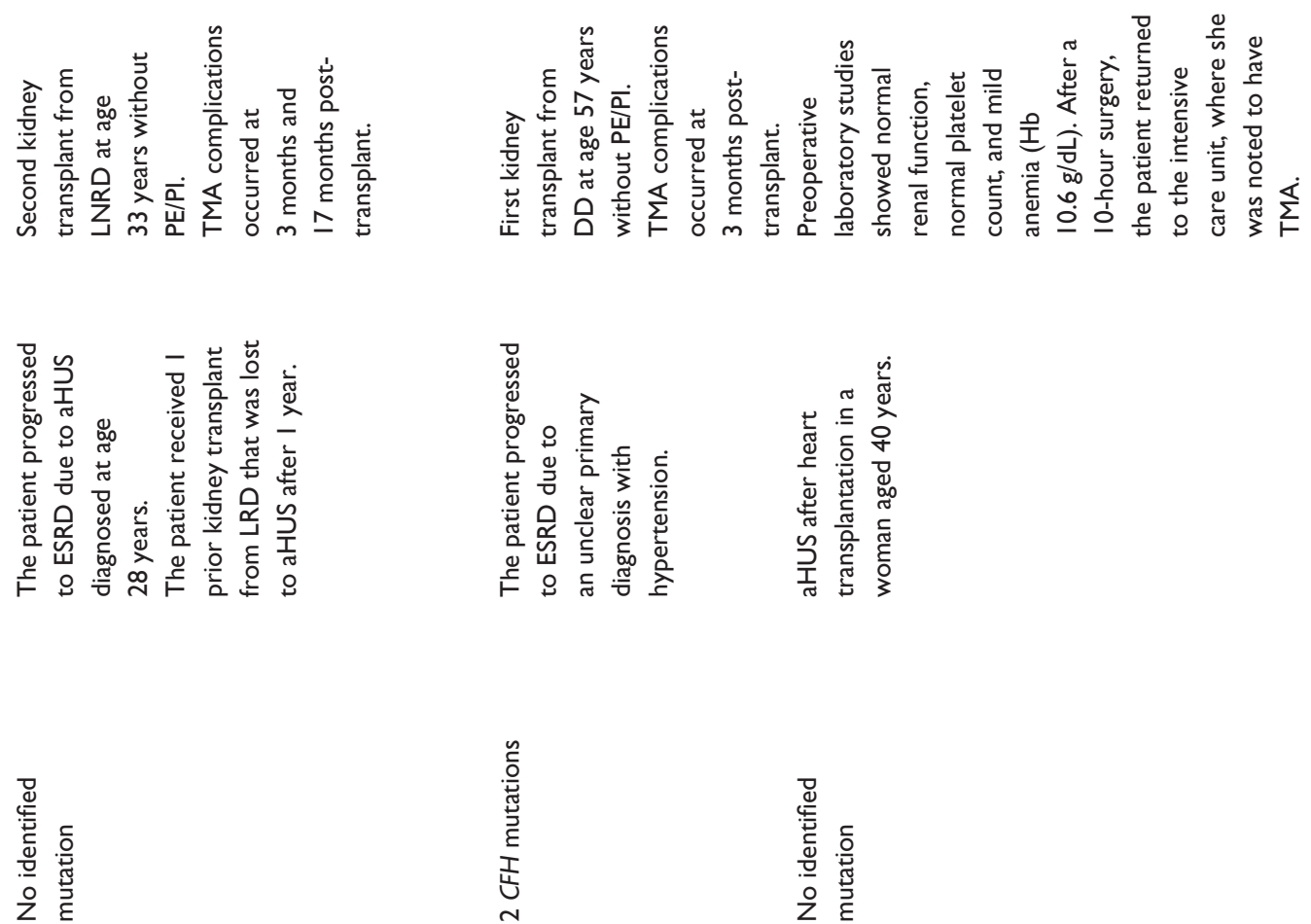

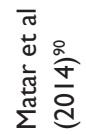

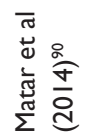

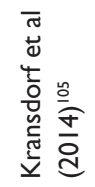




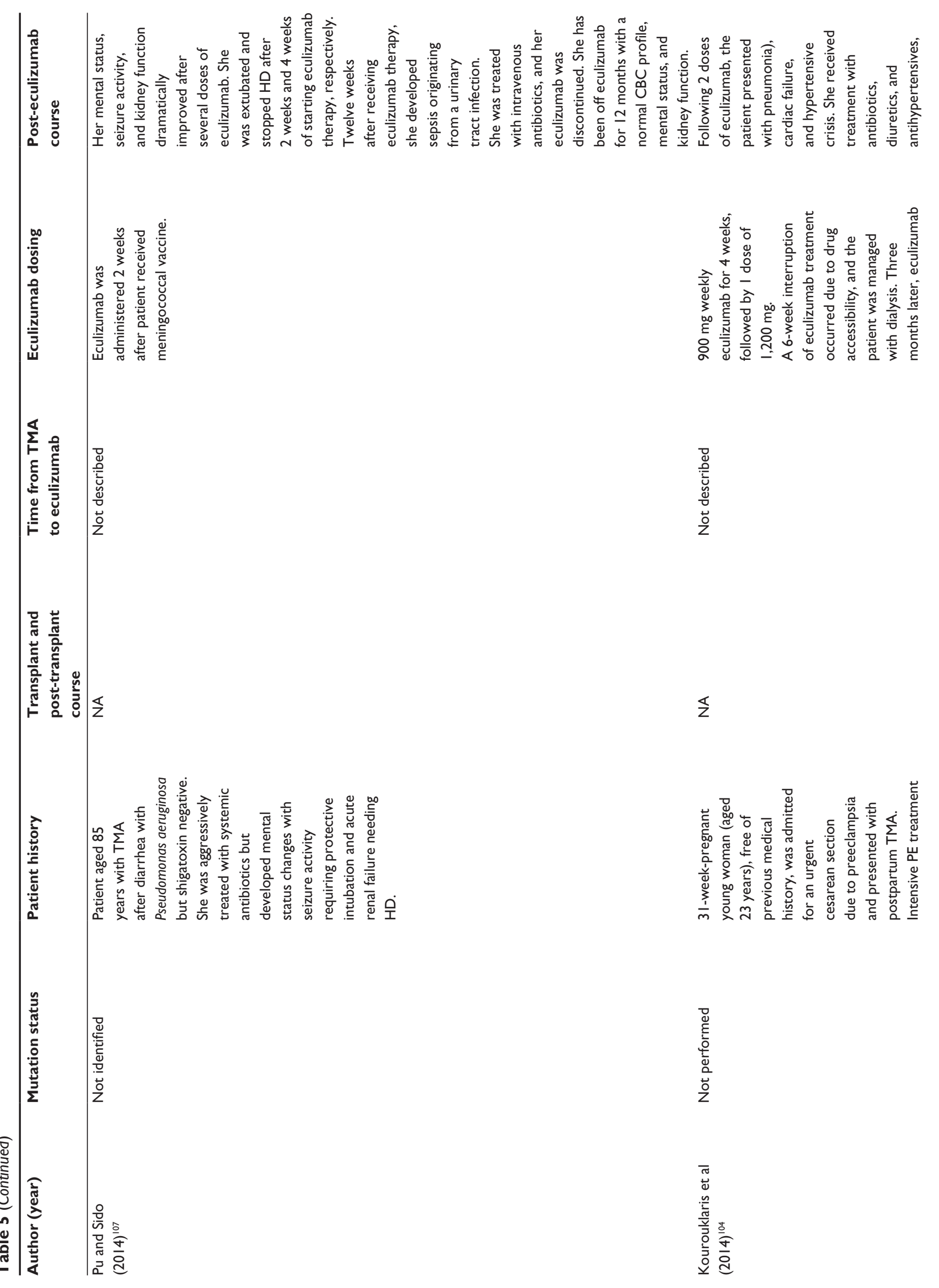



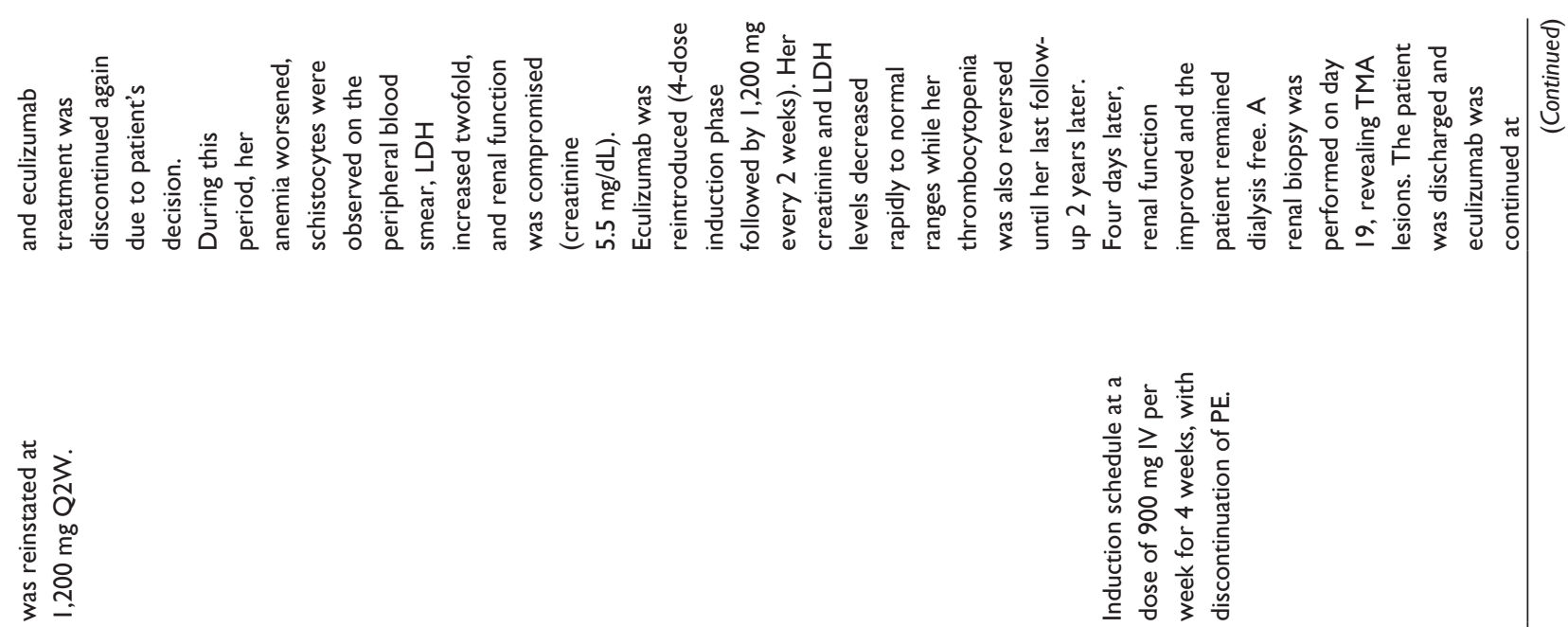

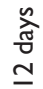

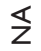
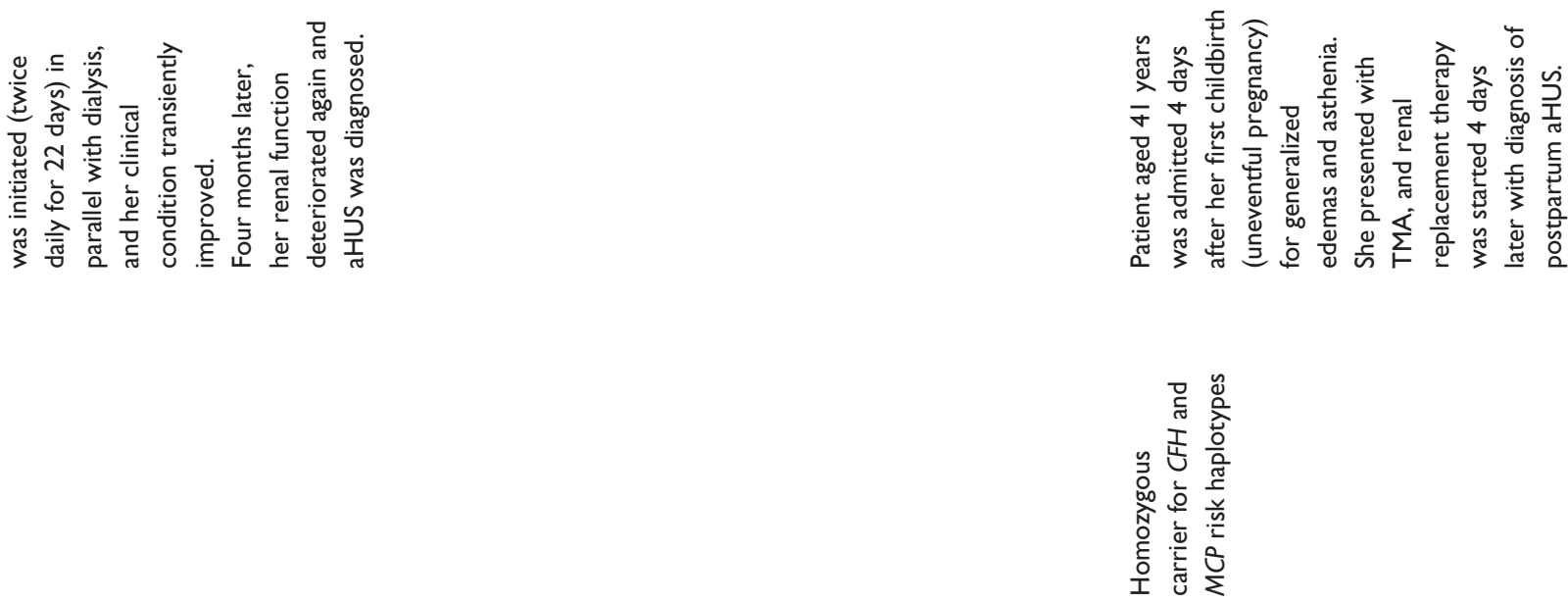

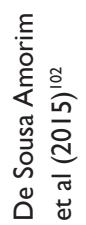




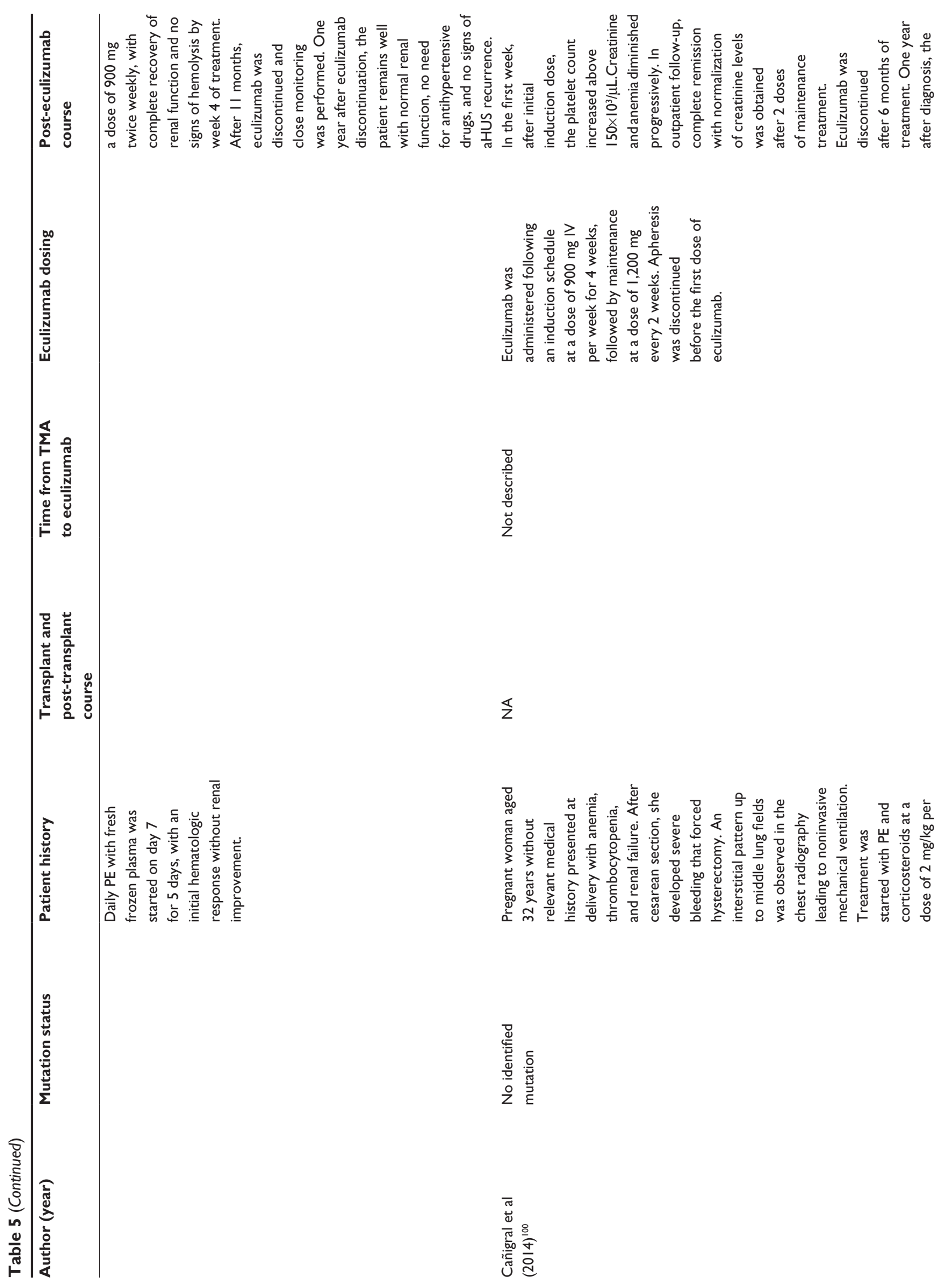



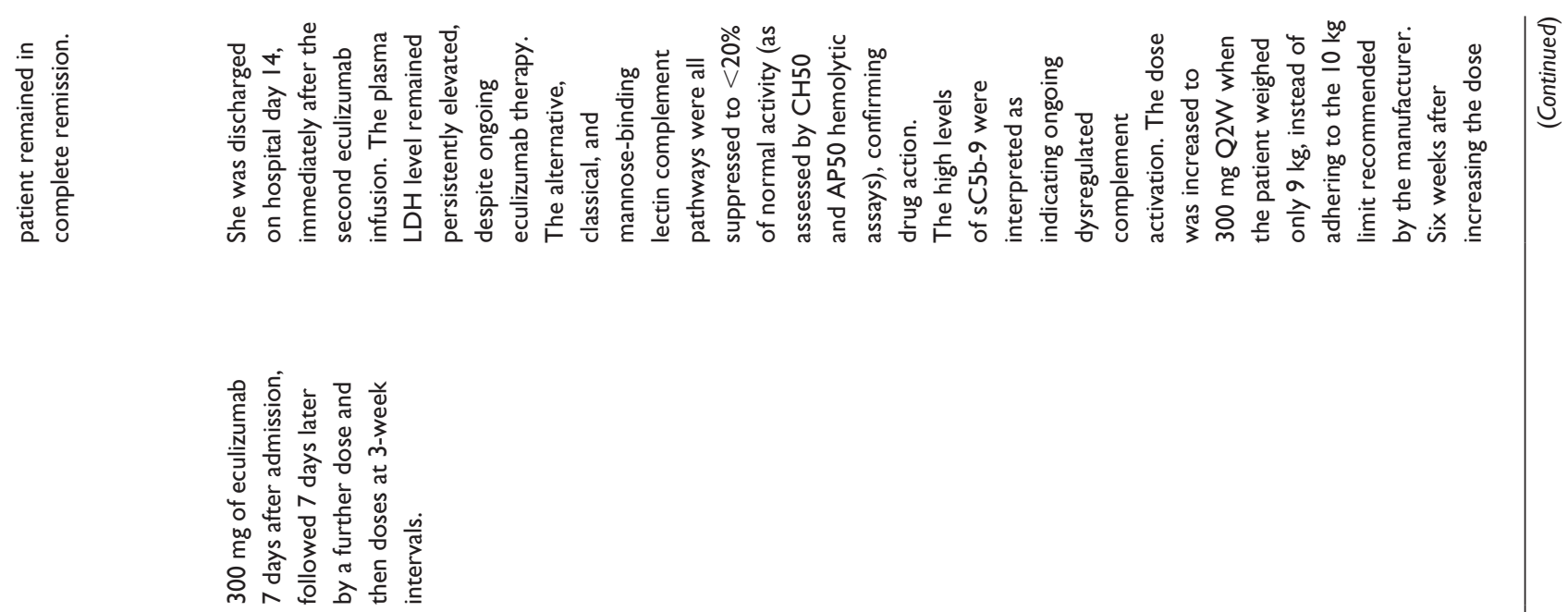

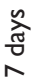

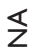

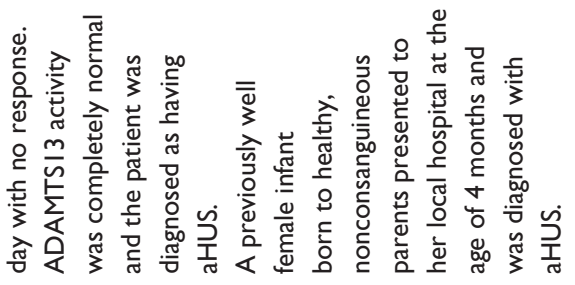

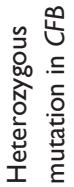

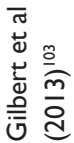




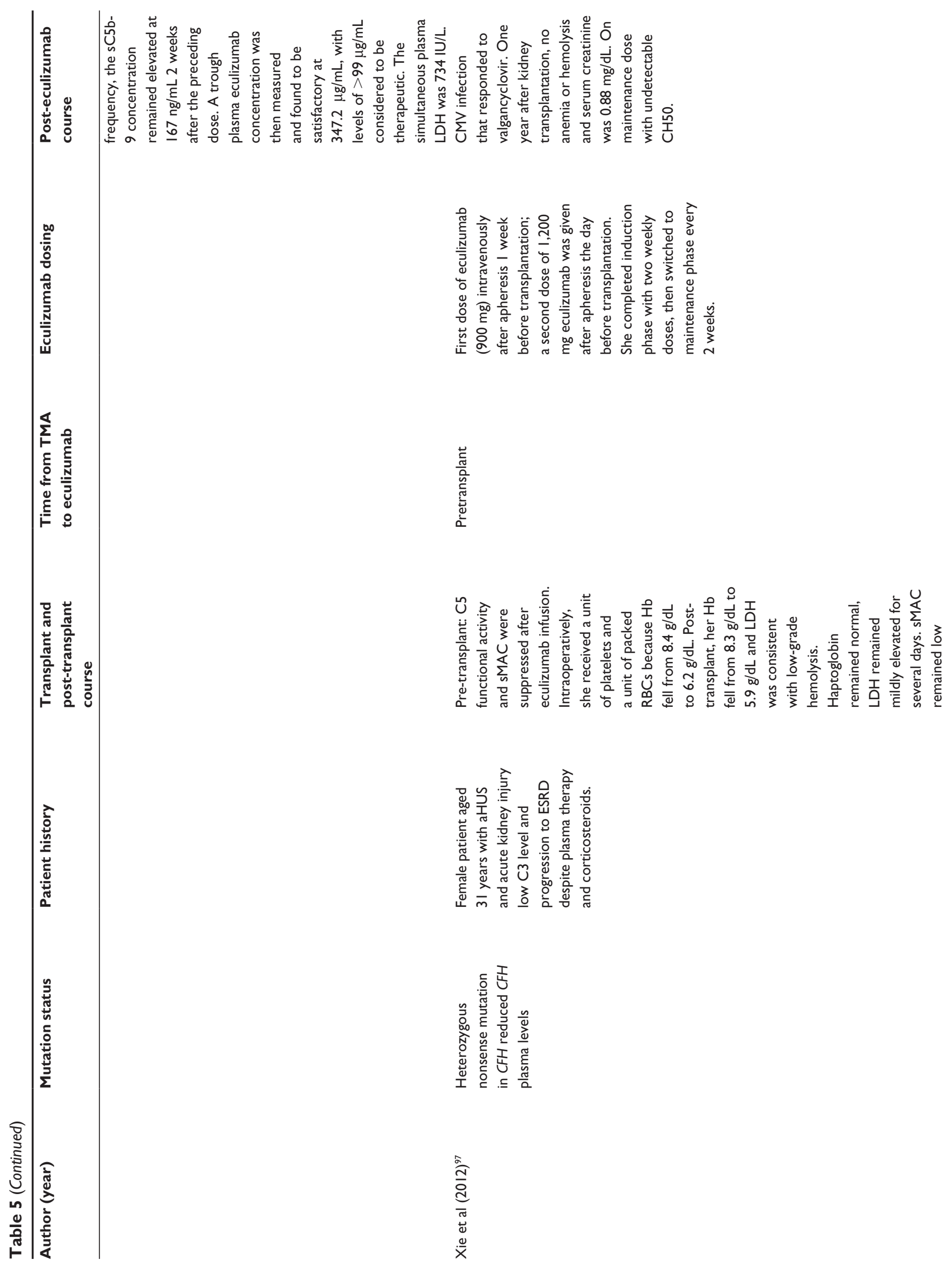



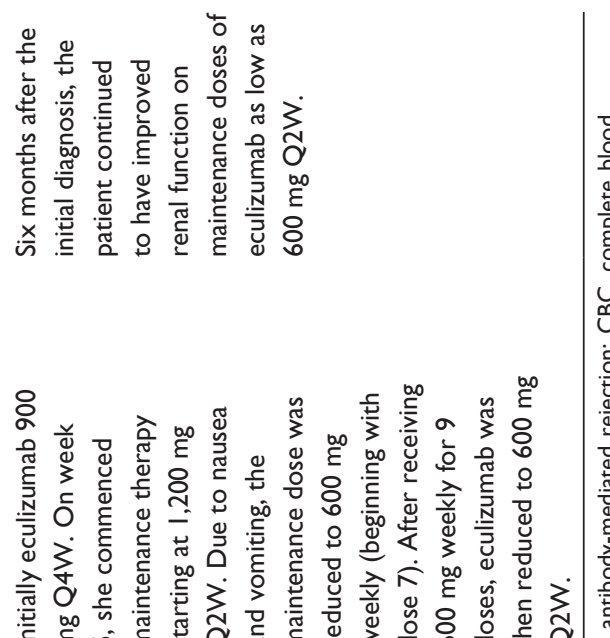

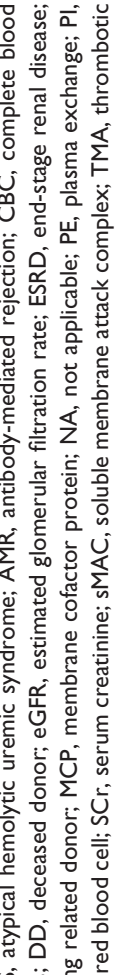

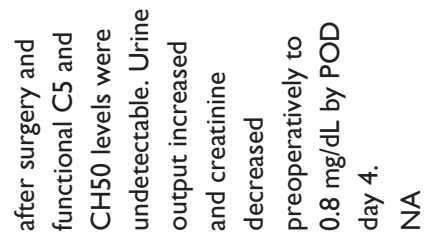

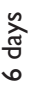

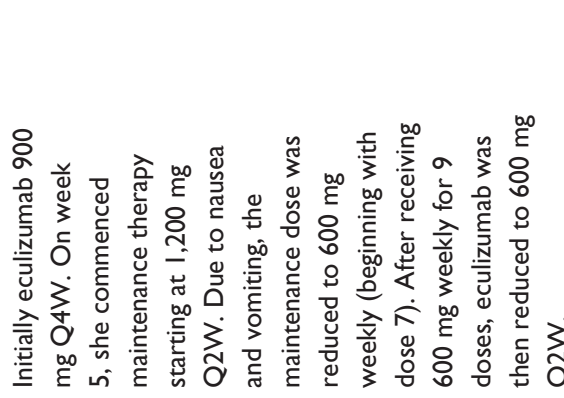

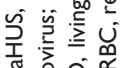

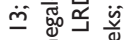

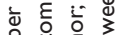
है ते 웡

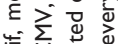

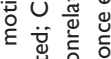

-

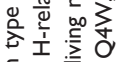

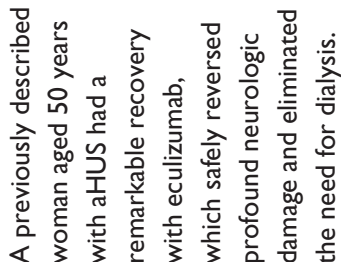

重 品

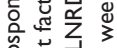

है हैं ญ्र

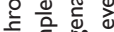

ช

专

至㐫

竞芒焉

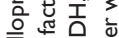

焉苍谣

हो

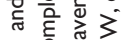

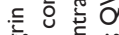

总至 $\geq$ 离

产蔼

ले 产 产

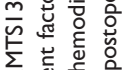

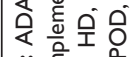

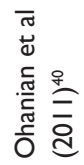

ชิ

훈

उ $\cup$ है

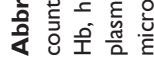


TMA complications and recommenced therapy with eculizumab (including two patients on dialysis who did not recover renal function but had ongoing hemolysis).

At the moment of publication, there were 45 patients (43 adults/two children) on dialysis in England whose primary diagnosis was aHUS. Mutations were identified in 32 (71\%) of patients. Of the 13 patients without an identified mutation, five $(38 \%)$ had lost a previous transplant to recurrent disease. This suggests that in these individuals there is an as-yet unidentified inherited or acquired factor that caused recurrent disease. The majority had not been wait-listed due to risk of subsequent TMA manifestations, and wait listing was made possible with the introduction of the NHS England Commissioning Policy for aHUS.

\section{Use of eculizumab prior to renal transplantation} In the report by Sheerin et al, ${ }^{13}$ from April 1, 2013, to March 31,2014 , nine of $45(20 \%)$ aHUS patients received a renal transplant with eight $(89 \%)$ receiving eculizumab prior to transplantation. One patient received eculizumab for subsequent TMA in the early postoperative period, and all of these renal transplant recipients had good transplant outcomes and continue to receive eculizumab.

\section{Treatment of prevalent patients not on dialysis}

Of the eleven patients with long-duration aHUS who were not on dialysis, eight received eculizumab to prevent further relapses. One of these was a patient with a known $C D 46$ mutation who had recurrent episodes of pancreatitis that did not respond to eculizumab, which was withdrawn. Three were transplant patients — one started eculizumab 29 months after transplant when a biopsy undertaken for progressive decline in transplant function showed evidence of a chronic TMA with graft function improvement after eculizumab; two other transplant patients (deemed to have typical HUS) developed a TMA in the graft early after transplantation leading to a revised primary renal diagnosis of aHUS, both of whom had good outcome with eculizumab treatment.

\section{Case reports of kidney transplant patients with aHUS treated with eculizumab}

Cases describing use of eculizumab in patients with aHUS prior to transplant and long-term use after kidney transplantation to prevent TMA and therefore the risk of allograft loss are summarized in Table 5. ${ }^{11,40,82,83,90,97,99-108}$ Of the 26 cases backed with adequate follow-up information, 24 patients $(92 \%)$ remained free of TMA complications with stable graft function at last follow-up (range, 3 days to 39 months). We refer you to the full publications for complete details.

Limited patient-level information was available in the case series presented by Sheerin et al; ${ }^{13}$ therefore, these are not presented in Table 5.

\section{Safety}

Terminal complement activity (MAC) is required for protection from invasive meningococcal disease, and use of eculizumab would heighten the exposure of patients to this risk. Immunization is required by regulatory authorities for the use of eculizumab, and antimicrobial prophylaxis is suggested in the early days after such immunization (on label). In the prospective trials, ${ }^{30}$ meningococcal infection, infection-related serious adverse events, and deaths were not reported, and this continued throughout the extension study. ${ }^{31}$ In trial 1 ("progressive TMA"), serious adverse events were reported in all patients, one of which was considered severe (hypertension in a chronically hypertensive patient). In trial 2 ("longstanding TMA"), half of the patients had serious adverse events. All serious adverse events related to eculizumab had resolution without interruption of the drug. Beyond the 26th week of treatment, no new adverse events were reported and were similar among different subgroups, including transplant recipients. It is noteworthy that adverse events were reported to diminish over time from week 26 to the 2-year cutoff, and no new or cumulative adverse events were noted. ${ }^{31}$

In the series published by Sheerin et $\mathrm{al}^{13}$ regarding the NHS England Commissioning Policy for aHUS, there were no meningococcal infections described in 43 patients treated with eculizumab and vaccinated according to local guidelines.

The presence of non-neutralizing human anti-human antibodies was confirmed in one patient in trial 1 who received a single dose of eculizumab and discontinued following diagnosis of systemic lupus erythematosus (an exclusion criterion).

In a 10-year-old boy with aHUS and heterozygous factor $\mathrm{H}$ mutation who received eculizumab to avoid recurrence of aHUS in the renal allograft, protective serum bactericidal antibody titers $(\geq 1: 8)$ were seen after kidney transplantation under immunosuppressive therapy with mycophenolate mofetil, tacrolimus, steroids, and eculizumab over a 27-month observational period. This case illustrates that a humoral immune response to conjugate meningococcus $\mathrm{C}$ vaccination may occur and be maintained despite chronic renal disease, kidney transplantation, immunosuppressive 
drugs, and immunomodulatory therapy with eculizumab. However, it remains unclear whether serologically defined protective serum bactericidal antibody titers mediate true protection from invasive meningococcal disease in an immunocompromised patient, particularly if undergoing treatment with a complement inhibitor. ${ }^{109}$

A 24-year-old man with diarrhea found to have acute renal failure with MAHA was diagnosed with aHUS. He was initiated on PE and hemodialysis. On day 6, he was started on eculizumab. His renal function progressively improved. His main complication during eculizumab therapy was hypertension-related posterior reversible encephalopathy syndrome. ${ }^{110}$

The complement system plays a vital role in preventing life-threatening infections by ensuring optimal functioning of the host immune system. Its dysregulation has been implicated in causing glomerular, hematologic, and transplant-related disorders. Vellanki and Bargman ${ }^{11}$ describe a very rare case of Aspergillus niger peritonitis in an ESRD patient on peritoneal dialysis receiving maintenance eculizumab therapy for aHUS. Given that murine models with the same defect as that induced by eculizumab are vulnerable to invasive aspergillosis, it is suggested that the fungal peritonitis in this patient was the result of the eculizumab therapy. ${ }^{111}$

The long-term safety and efficacy of eculizumab in the pediatric population remain under review. Cullinan et $\mathrm{al}^{59}$ presented the case of a child with a hybrid CFH/CFHR 3 gene who, having had multiple disease relapses despite optimal treatment with PE, commenced eculizumab therapy in August 2010. She remained relapse-free in follow-up at 52 months, and treatment has been well tolerated. Despite vaccination against meningococcal disease and appropriate antibiotic prophylaxis, the patient developed meningococcal bacteremia 30 months into treatment. She presented with nonspecific symptoms but recovered without sequelae with appropriate treatment. The authors suggest vaccination, antibiotic prophylaxis, and annual monitoring and follow-up of vaccine responses. ${ }^{59}$

A recently published case series in a pediatric population $^{112}$ described a possible relationship of liver injury with the use of eculizumab in eleven children treated with this drug for aHUS in a single center. Elevated liver enzymes were reported in seven children (ages 6-11 years) after starting eculizumab infusions to treat aHUS. Liver enzyme thresholds for drug-induced liver injury (international patterns) were exceeded in five cases, all of which were classified as mixed hepatocellular/cholestatic. Other causes for liver injury such as infections were excluded. One patient developed tender hepatomegaly and a 20-fold liver enzyme elevation after starting eculizumab. Recurrent liver injury following resumption of treatment with eculizumab led to its discontinuation and conversion to plasma therapy. Thus, hepatotoxicity in patients treated with eculizumab for aHUS should be monitored. Despite this clinical finding, further research is necessary to characterize the mechanism of potential hepatotoxicity and also to identify patients at risk. ${ }^{112}$

Eculizumab has been used in pregnant women successfully, albeit with $\mathrm{PNH}^{113}$ and not aHUS. Recently, a case report of safe use of eculizumab in a 26-week pregnant woman with aHUS was described. ${ }^{38}$

\section{Dose modification or eculizumab discontinuation}

In the prospective trials, ${ }^{31}$ the six patients in trial 1 ("progressive TMA") and two patients in trial 2 ("longstanding TMA") discontinued treatment with eculizumab, with no overt TMA reported up to 8 weeks after withdrawal.

In a separate cohort, Cugno et al ${ }^{114}$ used a complement activity assay (Wieslab) to measure alternative lectin-mannose and classical pathways in patients receiving eculizumab. Complement activity was completely suppressed at 1 week, 2 weeks, and 3 weeks after the last eculizumab infusion but only partially suppressed after 4 weeks.

The largest case series of eculizumab discontinuation was provided by Ardissino et a ${ }^{115}$ and Carr and Cataland, ${ }^{116}$ who published the outcome of eculizumab discontinuation in ten patients aiming at minimizing adverse reactions, including meningitis risk and infusion discomfort, and reducing costs. Patient monitoring was home-based and consisted of urine dipstick testing for blood. During the 95 months of observation, one-third of the patients experienced a relapse (median within 1.5 months), but recovery after eculizumab was restarted. More recently, Ardissino et a ${ }^{117}$ published the results of longer follow-up period after discontinuation, and a report of six additional cases. Patients had received eculizumab for a median of 4.3 months (range, 0.5-14.4 months). Eight patients were able to discontinue dialysis therapy, whereas the other eight had never been dialyzed. During a cumulative time off treatment of 243 months, five patients experienced relapse, identified by means of regular home urine dipstick testing, within 6 months of the last eculizumab dose (an average of one relapse per 49 months off therapy). In these patients, eculizumab therapy was restarted, followed by rapid improvement in serum creatinine levels and proteinuria to or below baseline values, and maintained every 3 weeks or 
4 weeks based on global complement activity. Eleven patients remained in remission with no signs of acute disease.

The authors concluded that, in aHUS, it is possible and relatively safe to discontinue eculizumab therapy. They discourage discontinuation of eculizumab therapy in kidney transplant recipients with $\mathrm{CFH}$ mutations and patients with glomerular filtration rates below $20 \mathrm{~mL} / \mathrm{min} / 1.73 \mathrm{~m}^{2}$. In patients with anti-CFH antibodies, one should consider discontinuation of eculizumab therapy when the antibody titer is $<2.5$ times ULN. Regular home urine dipstick monitoring is suggested for early identification of relapses, especially during acute illnesses and when patients feel unwell.

After the publication of this case series, Wetzels and van de $\operatorname{Kar}^{118}$ added data for eculizumab treatment discontinuation in patients with aHUS and a $C F H$ mutation. In their report, the authors treated four such patients who were plasma-resistant or -dependent and received eculizumab in accordance with FDA-proposed schedules. By local protocol, treatment is discontinued after 4-6 months if disease activity has disappeared and kidney function has improved and stabilized for at least 4-6 weeks. Eculizumab treatment was withdrawn in three of four patients, two of whom had no signs of disease activity as of their respective 11-month and 17-month follow-ups. Recurrent disease developed in one patient 3 months after eculizumab therapy discontinuation. When they compared these patients with those of Ardissino et al, ${ }^{117}$ they noted a difference in the location of the $\mathrm{CFH}$ mutations, suggesting that patients with a mutation in exons 19 or 20 may be more prone to recurrence.

There are reports of temporary use of eculizumab in drug-induced TMA. Faguer et $\mathrm{al}^{3}$ published on use of seven doses of eculizumab starting 30 days after mitomycin $\mathrm{C}$-induced TMA with reversal and no relapse after 1 year of follow-up. At the same time, Gilbert et $\mathrm{al}^{2}$ published the case of a 2-year-old patient with TMA after cisplatin therapy for neuroblastoma for whom eculizumab was administered for 2 months - there was a relapse 2 months after stopping eculizumab, and the patient was found to have a pathogenic variant in CD46, resuming treatment with complement blockade with good outcome.

Case reports of discontinuation of eculizumab in patients with aHUS are summarized in Table 5.

\section{Failure of response to eculizumab: possible underlying mechanisms}

When patients fail to respond to eculizumab or have frequent episodes of overt hemolysis during treatment, it is important to address the underlying mechanism of resistance, especially associated conditions that enhance complement responses such as infections, drugs, chemotherapy, or surgery, among others.

Mechanisms of TMA not primarily related to complement defects have been described in poor responders to eculizumab, such as methylmalonic aciduria and homocystinuria type $\mathrm{C}$ protein mutations with elevated homocysteine levels, which may occur even in adult-onset aHUS ${ }^{119}$ and in a case of monoclonal proteinuria. ${ }^{120}$

Although the underlying mechanism is still unknown, Schalk et $\mathrm{al}^{74}$ described a 3 -year-old boy with aHUS due to a novel heterozygous truncating complement Factor H mutation in combination with other changes known to be associated with an increased risk for aHUS. Despite eculizumab treatment and maximal suppression of the classical and alternative complement pathways, $\mathrm{C} 3 \mathrm{~d}$ and $\mathrm{sC} 5 \mathrm{~b}-9$ remained consistently elevated and were confirmed by augmented serum-induced endothelial C5b-9 deposits. The patient showed repeated relapses, reflected in ongoing activation in vivo, despite the full inhibition of global AP activity (CH50, APH50) in vitro. The authors state that no laboratory-confirmed parameter definitively reflects the situation on endothelial cells, where microangiopathy is localized. Nevertheless, the initial diagnosis of nonresponse was made on the basis of persistently low C3 (which is commonly seen after treatment), as well as other parameters not acceptably reliable. Insufficient data are given to judge whether relapses were indeed relapses or not.

In a cohort of 345 Japanese patients with $\mathrm{PNH}$ who received eculizumab, eleven patients had a poor response. All of them had a single missense $\mathrm{C} 5$ heterozygous mutation, whose prevalence among the patients with PNH (3.2\%) was similar to that among healthy Japanese persons (3.5\%), and which was also identified in the Han Chinese population. A patient of Asian ancestry in Argentina who had a poor response had a very similar mutation. Both $\mathrm{C} 5$ (with and without the mutation) caused hemolysis in vitro, but only $\mathrm{C} 5$ without the mutation was able to bind to and have its hydrolysis prevented by eculizumab. ${ }^{121}$ To date, similar mutations in $\mathrm{C} 5$ have not been described in patients with aHUS.

\section{Summary and conclusion}

The molecular understanding of the mechanism of TMA related to aHUS has led to the novel therapeutic application of a C5 inhibitor, eculizumab. Controlled clinical trials, following upon dozens of case reports and a few case series, confirm that aHUS may be controlled in the overwhelming majority of patients and likely at a higher frequency than with PE alone by historical database comparisons. Recent consensus guidelines and our extensive review support that 
the drug has become the treatment of choice for patients of all ages with aHUS.

Despite the impressive clinical outcomes using eculizumab in a variety of circumstances in patients with aHUS that were summarized in our review, there remain absent biomarkers of disease diagnosis, ongoing clinical activity, or response to the drug. As with all pharmacologic agents, risks and side effects may occur; however, in aHUS, these are largely outweighed by efficacy.

\section{Acknowledgments}

The authors would like to acknowledge Peloton Advantage, LLC, funded by Alexion Pharmaceuticals, Inc., for providing bibliographic support.

\section{Disclosure}

Lilian M Pereira Palma and Craig B Langman each report receiving honoraria for lectures from Alexion Pharmaceuticals, Inc.

\section{References}

1. Noris M, Remuzzi G. Glomerular diseases dependent on complement activation, including atypical hemolytic uremic syndrome, membranoproliferative glomerulonephritis, and $\mathrm{C} 3$ glomerulopathy: core curriculum 2015. Am J Kidney Dis. 2015;66(2):359-375.

2. Gilbert RD, Stanley LK, Fowler DJ, Angus EM, Hardy SA, Goodship TH. Cisplatin-induced haemolytic uraemic syndrome associated with a novel intronic mutation of treated with eculizumab. Clin Kidney $J$. 2013;6(4):421-425.

3. Faguer S, Huart A, Fremeaux-Bacchi V, Ribes D, Chaveau D. Eculizumab and drug-induced haemolytic-uraemic syndrome. Clin Kidney J. 2013;6(5):484-485.

4. Dahabreh I, Tsoutsos G, Tseligas D, Janinis D. Hemolytic uremic syndrome following the infusion of oxaliplatin: case report. BMC Clin Pharmacol. 2006;6:5.

5. Bu F, Borsa NG, Jones MB, et al. High-throughput genetic testing for thrombotic microangiopathies and $\mathrm{C} 3$ glomerulopathies. J Am Soc Nephrol. Epub 2015 Aug 17.

6. Jodele S, Zhang K, Zou F, et al. The genetic fingerprint of susceptibility for transplant-associated thrombotic microangiopathy. Blood. 2016;127(8):989-996.

7. Thomas TC, Rollins SA, Rother RP, et al. Inhibition of complement activity by humanized anti-C 5 antibody and single-chain Fv. Mol Immunol. 1996;33(17-18):1389-1401.

8. Rother RP, Rollins SA, Mojcik CF, Brodsky RA, Bell L. Discovery and development of the complement inhibitor eculizumab for the treatment of paroxysmal nocturnal hemoglobinuria. Nat Biotechnol. 2007;25(11):1256-1264.

9. US Food and Drug Administration. Soliris ${ }^{\circledR}$ (eculizumab) [prescribing information]. Cheshire, CT: Alexion Pharmaceuticals, Inc.; 2014.

10. European Medicines Agency. Soliris ${ }^{\circledR}$ (eculizumab) [summary of product characteristics]. Paris, France: Alexion Europe SAS; 2015.

11. Loirat C, Fakhouri F, Ariceta G, et al. An international consensus approach to the management of atypical hemolytic uremic syndrome in children. Pediatr Nephrol. 2016;31(1):15-39.

12. Peffault de Latour R, Fremeaux-Bacchi V, Porcher R, et al. Assessing complement blockade in patients with paroxysmal nocturnal hemoglobinuria receiving eculizumab. Blood. 2015;125(5): 775-783.
13. Sheerin NS, Kavanagh D, Goodship TH, Johnson S. A national specialized service in England for atypical haemolytic uraemic syndrome-the first year's experience. QJM. 2016;109(1):27-33.

14. Jodele S, Fukuda T, Vinks A, et al. Eculizumab therapy in children with severe hematopoietic stem cell transplantation-associated thrombotic microangiopathy. Biol Blood Marrow Transplant. 2014;20(4):518-525.

15. Noris M, Galbusera M, Gastoldi S, et al. Dynamics of complement activation in atypical HUS and how to monitor eculizumab therapy. Blood. 2014;124(11):1715-1726.

16. Bell WR, Braine HG, Ness PM, Kickler TS. Improved survival in thrombotic thrombocytopenic purpura-hemolytic uremic syndrome. Clinical experience in 108 patients. $N$ Engl J Med. 1991;325(6):398-403.

17. Schieppati A, Ruggenenti P, Cornejo RP, et al. Renal function at hospital admission as a prognostic factor in adult hemolytic uremic syndrome. The Italian Registry of Haemolytic Uremic Syndrome. J Am Soc Nephrol. 1992;2(11):1640-1644.

18. Taylor CM, Chua C, Howie AJ, Risdon RA; British Association for Paediatric Nephrology. Clinico-pathological findings in diarrhoea-negative haemolytic uraemic syndrome. Pediatr Nephrol. 2004;19(4):419-425.

19. Clark WF, Rock GA, Buskard N, et al. Therapeutic plasma exchange: an update from the Canadian Apheresis Group. Ann Intern Med. 1999;131(6):453-462.

20. Noris M, Caprioli J, Bresin E, et al. Relative role of genetic complement abnormalities in sporadic and familial aHUS and their impact on clinical phenotype. Clin J Am Soc Nephrol. 2010;5(10):1844-1859.

21. Ruebner RL, Kaplan BS, Copelovitch L. A time for reappraisal of "atypical" hemolytic uremic syndrome: should all patients be treated the same? Eur J Pediatr. 2012;171(10):1519-1525.

22. Baskin E, Gulleroglu K, Kantar A, Bayrakci U, Ozkaya O. Success of eculizumab in the treatment of atypical hemolytic uremic syndrome. Pediatr Nephrol. 2015;30(5):783-789.

23. Fremeaux-Bacchi V. [Pathophysiology of atypical hemolytic uremic syndrome. Ten years of progress, from laboratory to patient]. Biol Aujourdhui. 2013;207(4):231-240. French.

24. Szarvas N, Szilagyi A, Tasic V, et al. First-line therapy in atypical hemolytic uremic syndrome: consideration on infants with a poor prognosis. Ital J Pediatr. 2014;40:101.

25. Cataland SR, Holers VM, Geyer S, Yang S, Wu HM. Biomarkers of terminal complement activation confirm the diagnosis of aHUS and differentiate aHUS from TTP. Blood. 2014;123(24):3733-3738.

26. Caprioli J, Noris M, Brioschi S, et al. Genetics of HUS: the impact of MCP, CFH, and IF mutations on clinical presentation, response to treatment, and outcome. Blood. 2006;108(4):1267-1279.

27. Heinen S, Pluthero FG, van Eimeren VF, Quaggin SE, Licht C. Monitoring and modeling treatment of atypical hemolytic uremic syndrome. Mol Immunol. 2013;54(1):84-88.

28. Michon B, Moghrabi A, Winikoff R, et al. Complications of apheresis in children. Transfusion. 2007;47(10):1837-1842.

29. De S, Waters AM, Segal AO, Trautmann A, Harvey EA, Licht C. Severe atypical HUS caused by CFH S1191L - case presentation and review of treatment options. Pediatr Nephrol. 2010;25(1):97-104.

30. Legendre CM, Licht C, Muus P, et al. Terminal complement inhibitor eculizumab in atypical hemolytic-uremic syndrome. $N$ Engl $J$ Med. 2013;368(23):2169-2181.

31. Licht C, Greenbaum LA, Muus P, et al. Efficacy and safety of eculizumab in atypical hemolytic uremic syndrome from 2-year extensions of phase 2 studies. Kidney Int. 2015;87(5):1061-1073.

32. Alexion Pharmaceuticals [webpage on the Internet]. An open-label, multi-center clinical trial of eculizumab in adult patients with atypical hemolytic-uremic syndrome. Available from: http://clinicaltrials.gov/ ct2/show/NCT01194973?term=nct01194973\&rank=1. NLM identifier: NCT01194973. Accessed August 7, 2013.

33. Cofiell R, Kukreja A, Bedard K, et al. Eculizumab reduces complement activation, inflammation, endothelial damage, thrombosis, and renal injury markers in aHUS. Blood. 2015;125(21):3253-3262. 
34. Ardissino G, Wally Ossola M, Baffero GM, Rigotti A, Cugno M. Eculizumab for atypical hemolytic uremic syndrome in pregnancy. Obstet Gynecol. 2013;122(2 pt 2):487-489.

35. Ardissino G, Tel F, Testa S, et al. Skin Involvement in atypical hemolytic uremic syndrome. Am J Kidney Dis. 2014;63(4):652-655.

36. David R, Hochberg-Klein S, Amer R. Resolution of ocular involvement with systemic eculizumab therapy in atypical hemolytic-uremic syndrome. Eye (Lond). 2013;27(8):997-998.

37. Fakhouri F, Delmas Y, Provot F, et al. Insights from the use in clinical practice of eculizumab in adult patients with atypical hemolytic uremic syndrome affecting the native kidneys: an analysis of 19 cases. Am J Kidney Dis. 2014;63(1):40-48.

38. Mussoni MP, Veneziano FA, Boetti L, et al. Innovative therapeutic approach: sequential treatment with plasma exchange and eculizumab in a pregnant woman affected by atypical hemolytic-uremic syndrome. Transfus Apher Sci. 2014;51(2):134-136.

39. Nguyen MH, Mathew JJ, Denunzio TM, Carmichael MG. Diagnosis of atypical hemolytic uremic syndrome and response to eculizumab therapy. Hawaii J Med Public Health. 2014;73(9 suppl 1):22-24.

40. Ohanian M, Cable C, Halka K. Eculizumab safely reverses neurologic impairment and eliminates need for dialysis in severe atypical hemolytic uremic syndrome. Clin Pharmacol. 2011;3:5-12.

41. Povey H, Vundru R, Junglee N, Jibani M. Renal recovery with eculizumab in atypical hemolytic uremic syndrome following prolonged dialysis. Clin Nephrol. 2014;82(5):326-331.

42. Rafiq A, Tariq H, Abbas N, Shenoy R. Atypical hemolytic-uremic syndrome: a case report and literature review. Am J Case Rep. 2015;16:109-114.

43. Rigothier C, Delmas Y, Roumenina LT, et al. Distal angiopathy and atypical hemolytic uremic syndrome: clinical and functional properties of an anti-factor H IgAlambda antibody. Am J Kidney Dis. 2015;66(2):331-336.

44. Salem G, Flynn JM, Cataland SR. Profound neurological injury in a patient with atypical hemolytic uremic syndrome. Ann Hematol. 2013;92(4):557-558.

45. Sengul Samanci N, Ayer M, Ergen A, Ozturk S. An effective treatment of atypical hemolytic uremic syndrome with plasma exchange and eculizumab: a case report. Transfus Apher Sci. 2015;52(3): 314-316.

46. Sevinc M, Basturk T, Sahutoglu T, et al. Plasma resistant atypical hemolytic uremic syndrome associated with a $\mathrm{CFH}$ mutation treated with eculizumab: a case report. J Med Case Rep. 2015;9(1):92.

47. Thajudeen B, Sussman A, Bracamonte E. A case of atypical hemolytic uremic syndrome successfully treated with eculizumab. Case Rep Nephrol Urol. 2013;3(2):139-146.

48. Tsai HM, Kuo E. Eculizumab therapy leads to rapid resolution of thrombocytopenia in atypical hemolytic uremic syndrome. Adv Hematol. 2014;2014:1-7. [Article ID 295323].

49. Zschiedrich S, Prager EP, Kuehn EW. Successful treatment of the postpartum atypical hemolytic uremic syndrome with eculizumab. Ann Intern Med. 2013;159(1):76.

50. Al-Akash SI, Almond PS, Savell VH Jr, Gharaybeh SI, Hogue C. Eculizumab induces long-term remission in recurrent post-transplant HUS associated with C3 gene mutation. Pediatr Nephrol. 2011; 26(4):613-619.

51. Ariceta G, Arrizabalaga B, Aguirre M, Morteruel E, Lopez-Trascasa M. Eculizumab in the treatment of atypical hemolytic uremic syndrome in infants. Am J Kidney Dis. 2012;59(5):707-710.

52. Azukaitis K, Loirat C, Malina M, Adomaitiene I, Jankauskiene A. Macrovascular involvement in a child with atypical hemolytic uremic syndrome. Pediatr Nephrol. 2014;29(7):1273-1277.

53. Bekassy ZD, Kristoffersson AC, Cronqvist M, et al. Eculizumab in an anephric patient with atypical haemolytic uraemic syndrome and advanced vascular lesions. Nephrol Dial Transplant. 2013;28(11):2899-2907.

54. Belingheri M, Possenti I, Tel F, et al. Cryptic activity of atypical hemolytic uremic syndrome and eculizumab treatment. Pediatrics. 2014;133(6):e1769-e1771.
55. Besbas N, Gulhan B, Karpman D, et al. Neonatal onset atypical hemolytic uremic syndrome successfully treated with eculizumab. Pediatr Nephrol. 2013;28(1):155-158.

56. Cayci FS, Cakar N, Hancer VS, Uncu N, Acar B, Gur G. Eculizumab therapy in a child with hemolytic uremic syndrome and CFI mutation. Pediatr Nephrol. 2012;27(12):2327-2331.

57. Christmann M, Hansen M, Bergmann C, Schwabe D, Brand J, Schneider W. Eculizumab as first-line therapy for atypical hemolytic uremic syndrome. Pediatrics. 2014;133(6):e1759-e1763.

58. Coppo R, Peruzzi L, Amore A, et al. Dramatic effects of eculizumab in a child with diffuse proliferative lupus nephritis resistant to conventional therapy. Pediatr Nephrol. 2015;30(1):167-172.

59. Cullinan N, Gorman KM, Riordan M, Waldron M, Goodship THJ, Awan A. Case report: benefits and challenges of long-term eculizumab in atypical hemolytic uremic syndrome. Pediatrics. 2015;135(6):e1506-e1509.

60. Diamante Chiodini B, Davin JC, Corazza F, et al. Eculizumab in antifactor $h$ antibodies associated with atypical hemolytic uremic syndrome. Pediatrics. 2014;133(6):e1764-e1768.

61. Dorresteijn EM, van de Kar NC, Cransberg K. Eculizumab as rescue therapy for atypical hemolytic uremic syndrome with normal platelet count. Pediatr Nephrol. 2012;27(7):1193-1195.

62. Giordano M, Castellano G, Messina G, et al. Preservation of renal function in atypical hemolytic uremic syndrome by eculizumab: a case report. Pediatrics. 2012;130(5):e1385-e1388.

63. Gruppo RA, Rother RP. Eculizumab for congenital atypical hemolyticuremic syndrome. $N$ Engl J Med. 2009;360(5):544-546.

64. Gulleroglu K, Fidan K, Hancer VS, Bayrakci U, Baskin E, Soylemezoglu O. Neurologic involvement in atypical hemolytic uremic syndrome and successful treatment with eculizumab. Pediatr Nephrol. 2013;28(5):827-830.

65. Hisano M, Ashida A, Nakano E, et al. Autoimmune-type atypical hemolytic uremic syndrome treated with eculizumab as first-line therapy. Pediatr Int. 2015;57(2):313-317.

66. Hu H, Nagra A, Haq MR, Gilbert RD. Eculizumab in atypical haemolytic uraemic syndrome with severe cardiac and neurological involvement. Pediatr Nephrol. 2014;29(6):1103-1106.

67. Lapeyraque AL, Fremeaux-Bacchi V, Robitaille P. Efficacy of eculizumab in a patient with factor-H-associated atypical hemolytic uremic syndrome. Pediatr Nephrol. 2011;26(4):621-624.

68. Mache CJ, Acham-Roschitz B, Fremeaux-Bacchi V, et al. Complement inhibitor eculizumab in atypical hemolytic uremic syndrome. Clin J Am Soc Nephrol. 2009;4(8):1312-1316.

69. Malina M, Gulati A, Bagga A, Majid MA, Simkova E, Schaefer F. Peripheral gangrene in children with atypical hemolytic uremic syndrome. Pediatrics. 2013;131(1):e331-e335.

70. Michaux K, Bacchetta J, Javouhey E, Cochat P, Fremaux-Bacchi V, Sellier-Leclerc AL. Eculizumab in neonatal hemolytic uremic syndrome with homozygous factor $\mathrm{H}$ deficiency. Pediatr Nephrol. 2014;29(12):2415-2419.

71. Noone D, Al-Matrafi J, Tinckam K, et al. Antibody mediated rejection associated with complement factor h-related protein $3 / 1$ deficiency successfully treated with eculizumab. Am J Transplant. 2012;12(9):2546-2553.

72. Ohta T, Urayama K, Tada Y, et al. Eculizumab in the treatment of atypical hemolytic uremic syndrome in an infant leads to cessation of peritoneal dialysis and improvement of severe hypertension. Pediatr Nephrol. 2015;30(4):603-608.

73. Roman-Ortiz E, Mendizabal OS, Pinto S, Lopez-Trascasa M, SanchezCorral P, Rodriguez de CS. Eculizumab long-term therapy for pediatric renal transplant in aHUS with CFH/CFHR1 hybrid gene. Pediatr Nephrol. 2014;29(1):149-153.

74. Schalk G, Kirschfink M, Wehling C, et al. A complicated case of atypical hemolytic uremic syndrome with frequent relapses under eculizumab. Pediatr Nephrol. 2015;30(6):1039-1042.

75. Sharma S, Pradhan M, Meyers KE, Le Palma K, Laskin BL. Neonatal atypical hemolytic uremic syndrome from a factor $\mathrm{H}$ mutation treated with eculizumab. Clin Nephrol. 2015;84(9):181-185. 
76. Tschumi S, Gugger M, Bucher BS, Riedl M, Simonetti GD. Eculizumab in atypical hemolytic uremic syndrome: long-term clinical course and histological findings. Pediatr Nephrol. 2011;26(11): 2085-2088.

77. Vaisbich MH, Henriques LS, Watanabe A, et al. [Eculizumab for the treatment of atypical hemolytic uremic syndrome: case report and revision of the literature]. J Bras Nefrol. 2013;35(3):237-241.

78. Vilalta R, Lara E, Madrid A, et al. Long-term eculizumab improves clinical outcomes in atypical hemolytic uremic syndrome. Pediatr Nephrol. 2012;27(12):2323-2326.

79. Noris M, Remuzzi G. Managing and preventing atypical hemolytic uremic syndrome recurrence after kidney transplantation. Curr Opin Nephrol Hypertens. 2013;22(6):704-712.

80. Le Quintrec M, Zuber J, Moulin B, et al. Complement genes strongly predict recurrence and graft outcome in adult renal transplant recipients with atypical hemolytic and uremic syndrome. Am J Transplant. 2013;13(3):663-675.

81. Saland J. Liver-kidney transplantation to cure atypical HUS: still an option post-eculizumab? Pediatr Nephrol. 2014;29(3):329-332.

82. Zuber J, Le Quintrec M, Krid S, et al. Eculizumab for atypical hemolytic uremic syndrome recurrence in renal transplantation. Am J Transplant. 2012;12(12):3337-3354

83. Nurnberger J, Philipp T, Witzke O, et al. Eculizumab for atypical hemolytic-uremic syndrome. N Engl J Med. 2009;360(5):542-544.

84. Chatelet V, Lobbedez T, Fremeaux-Bacchi V, Ficheux M, Ryckelynck JP, Hurault de Ligny B. Eculizumab: safety and efficacy after 17 months of treatment in a renal transplant patient with recurrent atypical hemolytic-uremic syndrome: case report. Transplant Proc. 2010;42(10):4353-4355.

85. Legault DJ, Boelkins MR. Successful treatment of aHUS recurrence and arrest of plasma exchange resistant TMA post-renal transplantation with the terminal complement inhibitor eculizumab [abstract 2421]. Blood. 2009;114(suppl):2421.

86. Akchurin O, Dogra S, Kaskel F, Jan D, Greenstein S, Del Rio M. Preemptive use of eculizumab for living-donor kidney transplantation in a child with atypical hemolytic uremic syndrome. Einstein J Biol Med. 2015;30:22-25.

87. Alasfar S, Alachkar N. Atypical hemolytic uremic syndrome post-kidney transplantation: two case reports and review of the literature. Front Med (Lausanne). 2014;1:52.

88. Krid S, Roumenina LT, Beury D, et al. Renal transplantation under prophylactic eculizumab in atypical hemolytic uremic syndrome with CFH/CFHR1 hybrid protein. Am J Transplant. 2012;12(7): 1938-1944.

89. Mallett A, Hughes P, Szer J, et al. Atypical haemolytic uraemic syndrome treated with the complement inhibitor eculizumab: the experience of the Australian compassionate access cohort. Intern Med J. 2015;45(10):1054-1065.

90. Matar D, Naqvi F, Racusen LC, Carter-Monroe N, Montgomery RA, Alachkar N. Atypical hemolytic uremic syndrome recurrence after kidney transplantation. Transplantation. 2014;98(11):1205-1212.

91. Nester C, Stewart Z, Myers D, et al. Pre-emptive eculizumab and plasmapheresis for renal transplant in atypical hemolytic uremic syndrome. Clin J Am Soc Nephrol. 2011;6(6):1488-1494.

92. Parikova A, Fronek JP, Viklicky O. Living-donor kidney transplantation for atypical haemolytic uremic syndrome with pre-emptive eculizumab use. Transpl Int. 2015;28(3):366-369.

93. Pelicano MB, de Cordoba SR, Diekmann F, et al. Anti-C5 as prophylactic therapy in atypical hemolytic uremic syndrome in living-related kidney transplantation. Transplantation. 2013;96(4):e26-e29.

94. Ranch D, Crowther B, Arar M, Assanasen C. Prophylactic eculizumab for kidney transplantation in a child with atypical hemolytic uremic syndrome due to complement factor $\mathrm{H}$ mutation. Pediatr Transplant. 2014;18(6):E185-E189.

95. Tran H, Chaudhuri A, Concepcion W, Grimm PC. Use of eculizumab and plasma exchange in successful combined liver-kidney transplantation in a case of atypical HUS associated with complement factor $\mathrm{H}$ mutation. Pediatr Nephrol. 2014;29(3):477-480.
96. Weitz M, Amon O, Bassler D, Koenigsrainer A, Nadalin S. Prophylactic eculizumab prior to kidney transplantation for atypical hemolytic uremic syndrome. Pediatr Nephrol. 2011;26(8):1325-1329.

97. Xie L, Nester CM, Reed AI, Zhang Y, Smith RJ, Thomas CP. Tailored eculizumab therapy in the management of complement factor H-mediated atypical hemolytic uremic syndrome in an adult kidney transplant recipient: a case report. Transplant Proc. 2012;44(10): 3037-3040.

98. Zimmerhackl LB, Hofer J, Cortina G, et al. Prophylactic eculizumab after renal transplantation in atypical hemolytic-uremic syndrome. N Engl J Med. 2010;362(18):1746-1748.

99. Alachkar N, Bagnasco SM, Montgomery RA. Eculizumab for the treatment of two recurrences of atypical hemolytic uremic syndrome in a kidney allograft. Transpl Int. 2012;25(8):e93-e95.

100. Canigral C, Moscardo F, Castro C, et al. Eculizumab for the treatment of pregnancy-related atypical hemolytic uremic syndrome. Ann Hematol. 2014;93(8):1421-1422.

101. Chandran S, Baxter-Lowe L, Olson JL, Tomlanovich SJ, Webber A. Eculizumab for the treatment of de novo thrombotic microangiopathy post simultaneous pancreas-kidney transplantation - a case report. Transplant Proc. 2011;43(5):2097-2101.

102. De Sousa Amorim E, Blasco M, Quintana L, Sole M, de Cordoba SR, Campistol JM. Eculizumab in pregnancy-associated atypical hemolytic uremic syndrome: insights for optimizing management. J Nephrol. 2015;28(5):641-645.

103. Gilbert RD, Fowler DJ, Angus E, Hardy SA, Stanley L, Goodship TH Eculizumab therapy for atypical haemolytic uraemic syndrome due to a gain-of-function mutation of complement factor B. Pediatr Nephrol. 2013;28(8):1315-1318.

104. Kourouklaris A, Ioannou K, Athanasiou I, Panagidou A, Demetriou K, Zavros M. Postpartum thrombotic microangiopathy revealed as atypical hemolytic uremic syndrome successfully treated with eculizumab: a case report. J Med Case Rep. 2014;8:307.

105. Kransdorf EP, Kittleson MM, Kobashigawa JA. Atypical hemolyticuremic syndrome immediately after heart transplantation. $J$ Heart Lung Transplant. 2014;33(6):664-665.

106. Larrea CF, Cofan F, Oppenheimer F, Campistol JM, Escolar G, Lozano M. Efficacy of eculizumab in the treatment of recurrent atypical hemolytic-uremic syndrome after renal transplantation. Transplantation. 2010;89(7):903-904.

107. Pu JJ, Sido A. Successful discontinuation of eculizumab therapy in a patient with aHUS. Ann Hematol. 2014;93(8):1423-1425.

108. Wilson C, Torpey N, Jaques B, et al. Successful simultaneous liverkidney transplant in an adult with atypical hemolytic uremic syndrome associated with a mutation in complement factor H. Am J Kidney Dis. 2011;58(1):109-112.

109. Zlamy M, Hofer J, Elias J, et al. Immunogenicity of meningococcus $\mathrm{C}$ vaccination in a patient with atypical hemolytic uremic syndrome (aHUS) on eculizumab therapy. Pediatr Transplant. 2012;16(6):E246-E250.

110. Sajan T, Vinay S, Sonu N, Alan P. How atypical can atypical hemolytic uremic syndrome be? Clin Case Rep. 2014;2(2):57-59.

111. Vellanki VS, Bargman JM. Aspergillus niger peritonitis in a peritoneal dialysis patient treated with eculizumab. Ren Fail. 2014;36(4):631-633.

112. Hayes W, Tschumi S, Ling SC, Feber J, Kirschfink M, Licht C. Eculizumab hepatotoxicity in pediatric aHUS. Pediatr Nephrol. 2015;30(5):775-781.

113. Hallstensen RF, Bergseth G, Foss S, et al. Eculizumab treatment during pregnancy does not affect the complement system activity of the newborn. Immunobiology. 2015;220(4):452-459.

114. Cugno M, Gualtierotti R, Possenti I, et al. Complement functional tests for monitoring eculizumab treatment in patients with atypical hemolytic uremic syndrome. J Thromb Haemost. 2014;12(9): 1440-1448.

115. Ardissino G, Testa S, Possenti I, et al. Discontinuation of eculizumab maintenance treatment for atypical hemolytic uremic syndrome: a report of 10 cases. Am J Kidney Dis. 2014;64(4):633-637. 
116. Carr R, Cataland SR. Relapse of aHUS after discontinuation of therapy with eculizumab in a patient with aHUS and factor $\mathrm{H}$ mutation. Ann Hematol. 2013;92(6):845-846.

117. Ardissino G, Possenti I, Tel F, Testa S, Salardi S, Ladisa V. Discontinuation of eculizumab treatment in atypical hemolytic uremic syndrome: an update. Am J Kidney Dis. 2015;66(1):172-173.

118. Wetzels JF, van de Kar NC. Discontinuation of eculizumab maintenance treatment for atypical hemolytic uremic syndrome. Am J Kidney Dis. 2015;65(2):342.
119. Cornec-Le Gall E, Delmas Y, De Parscau L, et al. Adult-onset eculizumab-resistant hemolytic uremic syndrome associated with cobalamin C deficiency. Am J Kidney Dis. 2014;63(1):119-123.

120. Cheungpasitporn W, Leung N, Sethi S, Gertz MA, Fervenza FC. Refractory atypical hemolytic uremic syndrome with monoclonal gammopathy responsive to bortezomib-based therapy. Clin Nephrol. 2015;83(6):363-369.

121. Nishimura J, Yamamoto M, Hayashi S, et al. Genetic variants in C5 and poor response to eculizumab. $N$ Engl J Med. 2014;370(7):632-639.

\section{Publish your work in this journal}

The Journal of Blood Medicine is an international, peer-reviewed, open access, online journal publishing laboratory, experimental and clinical aspects of all topics pertaining to blood based medicine including but not limited to: Transfusion Medicine; Blood collection, Donor issues, Transmittable diseases, and Blood banking logistics; Immunohematology; Artificial and alternative

\section{Dovepress}

blood based therapeutics; Hematology; Biotechnology/nanotechnology of blood related medicine; Legal aspects of blood medicine; Historical perspectives. The manuscript management system is completely online and includes a very quick and fair peer-review system. Visit http://www.dovepress.com/ testimonials.php to read real quotes from published authors.

Submit your manuscript here: http://www.dovepress.com/Journal-of-blood-medicine-journal 